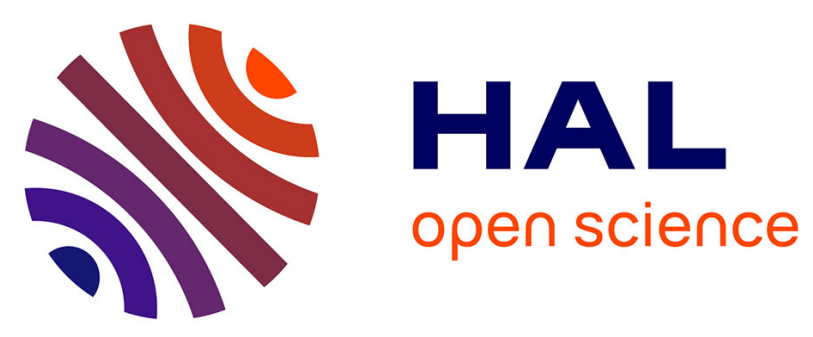

\title{
Intermittent hypoxia-related alterations in vascular structure and function: a systematic review and metaanalysis of rodent data
}

Olfa Harki, Quentin Boete, Jean-Louis Pépin, Claire Arnaud, Elise Belaidi, Gilles Faury, Charles Khouri, Anne Briançon-Marjollet

\section{To cite this version:}

Olfa Harki, Quentin Boete, Jean-Louis Pépin, Claire Arnaud, Elise Belaidi, et al.. Intermittent hypoxia-related alterations in vascular structure and function: a systematic review and metaanalysis of rodent data. European Respiratory Journal, 2021, 58 (4), pp.2100866. 10.1183/13993003.008662021. hal-03428303

\section{HAL Id: hal-03428303 \\ https://hal.univ-grenoble-alpes.fr/hal-03428303}

Submitted on 15 Nov 2021

HAL is a multi-disciplinary open access archive for the deposit and dissemination of scientific research documents, whether they are published or not. The documents may come from teaching and research institutions in France or abroad, or from public or private research centers.
L'archive ouverte pluridisciplinaire HAL, est destinée au dépôt et à la diffusion de documents scientifiques de niveau recherche, publiés ou non, émanant des établissements d'enseignement et de recherche français ou étrangers, des laboratoires publics ou privés. 


\section{(ii) EUROPEAN RESPIRATORY journal \\ OFFICIAL SCIENTIFIC IOURNAL OF THE ERS}

\section{Intermittent hypoxia-related alterations in vascular structure and function: a systematic review and meta- analysis of rodent data}

\begin{tabular}{|c|c|}
\hline Journal: & European Respiratory Journal \\
\hline Manuscript ID & Draft \\
\hline Manuscript Type: & Review \\
\hline $\begin{array}{l}\text { Date Submitted by the } \\
\text { Author: }\end{array}$ & $\mathrm{n} / \mathrm{a}$ \\
\hline Complete List of Authors: & $\begin{array}{l}\text { Harki, Olfa; Universite Grenoble Alpes, HP2 laboratory, faculty of } \\
\text { medicine } \\
\text { Boete, Quentin; Université Grenoble Alpes, Laboratoire HP2 } \\
\text { PEPIN, Jean-Louis; Universite Grenoble Alpes, } \\
\text { Arnaud, Claire; Université Grenoble Alpes, Laboratoire HP2; INSERM } \\
\text { U1042, } \\
\text { Belaidi, Elise; Université Grenoble Alpes, Laboratoire HP2 } \\
\text { Faury, Gilles; Universite Grenoble Alpes, Laboratoire HP2, UGA, Facultés } \\
\text { de medecine et de pharmacie } \\
\text { Khouri, Charles; Centre Hospitalier Universitaire Grenoble Alpes, } \\
\text { Pharmacovigilance; Universite Grenoble Alpes, HP2 } \\
\text { Briançon-Marjollet, Anne; Universite Grenoble Alpes, HP2 Laboratory, } \\
\text { faculty of medicine }\end{array}$ \\
\hline Key Words: & $\begin{array}{l}\text { systematic review, meta-analysis, intermittent hypoxia, arterial } \\
\text { pressure, vascular reactivity, vascular remodeling }\end{array}$ \\
\hline Abstract: & $\begin{array}{l}\text { Obstructive Sleep Apnea and the related intermittent hypoxia (IH) are } \\
\text { widely recognized as risk factors for incident cardiovascular diseases. } \\
\text { Numerous studies support the deleterious vascular impact of IH in } \\
\text { rodents but an overall interpretation is challenging owing to } \\
\text { heterogeneity in rodent species investigated and the severity and } \\
\text { duration of IH exposure. } \\
\text { To clarify this major issue, we conducted a systematic review and meta- } \\
\text { analysis to quantify the impact of IH on systemic artery structure and } \\
\text { function depending on the different IH exposure designs. } \\
\text { We searched PubMed and included } 104 \text { articles in a meta-analysis, } \\
\text { among them } 92 \text { using wild-type rodents and } 12 \text { using Apolipoprotein E } \\
\text { knock-out mice. We used the standardized mean difference (SMD) to } \\
\text { compare results between studies. } \\
\text { IH significantly increased mean arterial pressure ( }+13.77 \text { mmHg ( } 95 \% \\
\text { CI [11.73; } 15.82] \text { ), systolic and diastolic blood pressure. Meta- } \\
\text { regressions showed that hypoxia severity (FiO2) was associated with } \\
\text { mean arterial pressure. IH altered vasodilation in males but not in } \\
\text { females, and increased endothelin-1-induced, but not phenylephrine- } \\
\text { induced, vasoconstriction. Intima-media thickness significantly increased } \\
\text { upon IH exposure (SMD } 1.05, \text { CI [0.52; } 1.58] \text {, absolute values: }+3.23 \\
\mu m(1.61-5.00) \text { ). This increase was observed in mice but not in rats, and }\end{array}$ \\
\hline
\end{tabular}


was negatively associated with age. Finally $\mathrm{IH}$ increased atherosclerotic plaque size in ApoE-/- mice (SMD 1.1, CI [0.82; 1.41]).

To conclude, our meta-analysis established that $\mathrm{IH}$, independently of other confounders, has a strong effect on vascular structure and physiology. Our findings support the interest of identifying and treating sleep apnea in routine cardiology practice.

\section{SCHOLARONE \\ Manuscripts}


Professor Martin Kolb

Editor-in Chief

European Respiratory Journal

Dear Professor Kolb,

We are pleased to submit our manuscript entitled "Intermittent hypoxia-related alterations in vascular structure and function: a systematic review and meta-analysis of rodent data", by O. Harki et al., for your consideration for publication as a review article in the European Respiratory Journal.

Intermittent hypoxia is a key feature of Obstructive Sleep Apnea (OSA), a very common respiratory disease associated with major cardiovascular morbidity and mortality. Among OSA complications are hypertension, atherosclerosis, and myocardial infarction. However, clinical studies are often partly flawed by confounders and the role of $\mathrm{IH}$ as an independent cardiovascular risk factor is still debated. Numerous studies support the deleterious vascular impact of $\mathrm{IH}$ in rodents but an overall interpretation is challenging owing to heterogeneity in the rodent species investigated and the severity and duration of $\mathrm{IH}$ exposure. It thus appeared as crucial to establish from robust and consistent experimental data the role of $\mathrm{IH}$ in increasing cardiovascular risk so as to better understand its contribution toward cardiovascular diseases.

In this paper, we report a meta-analysis on rodent data to assess the impact of intermittent hypoxia $(\mathrm{IH})$ on vascular structure and function. We included more than 100 studies in which rodents were exposed to $\mathrm{IH}$ and various vascular parameters were examined, the main ones being arterial pressure, arterial reactivity to vasodilators or vasoconstrictors, vascular remodeling, and atherosclerosis lesions in ApoE -/- mice.

In our study, we clearly demonstrate that $\mathrm{IH}$, independently of confounders, has a major impact on systemic artery structure and function. Our findings support the interest of identifying and treating sleep apnea in routine cardiology practice.

Therefore, we think our results could raise much interest in the large community of both clinicians and researchers working in the fields of sleep apnea and of vascular physiopathology. We thus hope that you will consider our manuscript as well suited for publication in ERJ.

We suggest the following reviewers for this paper:

Dr Luciano Drager, University of Sao Paulo, luciano.drager@incor.usp.br

Dr Jan Polak, Faculty of Medicine, Prague, jan.polak@lf3.cuni.cz

Pr Ramon Farré, University of Barcelona, rfarre@ub.edu

Pr Frédéric Gagnadoux, University of Angers, frederic.gagnadoux@univ-angers.fr

We confirm that this article is not under consideration for publication in whole or in part elsewhere in any form. All authors have seen and approved submission of the manuscript to ERJ.

We look forward to your reply,

Respectfully yours, 


\section{Intermittent hypoxia-related alterations in vascular structure and function: a systematic review and meta-analysis of rodent data}

Olfa Harki ${ }^{1}$, Quentin Boete ${ }^{1}$, Jean-Louis Pépin ${ }^{1}$, Claire Arnaud ${ }^{1}$, Elise Belaidi ${ }^{1}$, Gilles Faury ${ }^{1}$, Charles Khouri $^{1,2 *}$, Anne Briançon-Marjollet ${ }^{1 *}$

${ }^{1}$ Univ. Grenoble Alpes, INSERM , CHU Grenoble Alpes, HP2, 38000 Grenoble, France

2 Pharmacovigilance Unit \& Clinical Pharmacology Department, Grenoble Alpes University Hospital, Grenoble, France

*Co-last authors have equally contributed to the work.

\section{Corresponding authors:}

Dr Anne Briançon-Marjollet Laboratoire HP2, INSERM U1300

Bâtiment Jean Roget, Site Santé La Tronche 38042 Grenoble Cedex 9

France

anne.briancon@univ-grenoble-alpes.fr

+33476637475

Twitter@LaboratoireHP2

Dr Charles Khouri

Centre Régional de Pharmacovigilance, CHU Grenoble Alpes

38043 Grenoble Cedex 09, France

Tel : +33476765145

CKhouri@chu-grenoble.fr

\section{Abbreviated title: Intermittent hypoxia alters vascular structure and function}

Key Words: Systematic review, meta-analysis, intermittent hypoxia, arterial pressure, vascular reactivity, vascular remodeling.

Take-home message : Our meta-analysis of rodent studies firmly establishes that intermittent hypoxia, as a model of obstructive sleep apnea, alters vascular pressure, remodeling and reactivity. Severity of $\mathrm{IH}$ and rodent characteristics contribute to this impact.

Word count : 4389 


\begin{abstract}
Obstructive Sleep Apnea and the related intermittent hypoxia $(\mathrm{IH})$ are widely recognized as risk factors for incident cardiovascular diseases. Numerous studies support the deleterious vascular impact of $\mathrm{IH}$ in rodents but an overall interpretation is challenging owing to heterogeneity in rodent species investigated and the severity and duration of $\mathrm{IH}$ exposure.

To clarify this major issue, we conducted a systematic review and meta-analysis to quantify the impact of $\mathrm{IH}$ on systemic artery structure and function depending on the different $\mathrm{IH}$ exposure designs.
\end{abstract}

We searched PubMed and included 104 articles in a meta-analysis, among them 92 using wildtype rodents and 12 using Apolipoprotein E knock-out mice. We used the standardized mean difference (SMD) to compare results between studies.

IH significantly increased mean arterial pressure $(+13.77 \mathrm{mmHg}(95 \% \mathrm{Cl}[11.73 ; 15.82])$, systolic and diastolic blood pressure. Meta-regressions showed that hypoxia severity $\left(\mathrm{FiO}_{2}\right)$ was associated with mean arterial pressure. IH altered vasodilation in males but not in females, and increased endothelin-1-induced, but not phenylephrine-induced, vasoconstriction. Intima-media thickness significantly increased upon IH exposure (SMD 1.05, $\mathrm{Cl}[0.52 ; 1.58]$, absolute values: $+3.23 \mu \mathrm{m}(1.61-5.00))$. This increase was observed in mice but not in rats, and was negatively associated with age. Finally IH increased atherosclerotic plaque size in ApoE-/- mice (SMD 1.1, $\mathrm{Cl}[0.82 ; 1.41])$.

To conclude, our meta-analysis established that IH, independently of other confounders, has a strong effect on vascular structure and physiology. Our findings support the interest of identifying and treating sleep apnea in routine cardiology practice. 


\section{Introduction}

Obstructive Sleep Apnea Syndrome (OSAS) is one of the most frequent chronic diseases, affecting up to nearly one billion individuals worldwide, ${ }^{1}$ and is characterized by the repetitive occurrence of apneas and hypopneas during sleep ${ }^{2}$. OSAS is widely recognized as a risk factor for prevalent and incident cardiovascular (CV) diseases including hypertension, atherogenesis, stroke, and myocardial infarction, thus leading to increased morbidity and mortality ${ }^{2-4}$. Among OSAS pathophysiological mechanisms, intermittent hypoxia $(\mathrm{IH})$ caused by repetitive hypoxia-reoxygenation cycles is thought to be the key intermediary mechanism leading to $\mathrm{CV}$ morbidity and mortality. However, clinical studies are frequently partly flawed by confounders and the role of $\mathrm{IH}$ as an independent cardiovascular risk factor is still debated. It is crucial to establish from robust and consistent experimental data the role of $\mathrm{IH}$ in increasing cardiovascular risk so as to better understand its contribution toward cardiovascular diseases.

Among OSA animal models developed in the last decades ${ }^{5}, \mathrm{IH}$ exposure in rodents is by far the most commonly used worldwide. Studies on rodents exposed to IH have allowed to dissect the contribution of different pathophysiological pathways and intermediary mechanisms, such as sympathetic nervous system activation, endothelial dysfunction, inflammation, or oxidative stress in triggering CV consequences. Many studies using animal models have supported the hypothesis that IH might be responsible for increased arterial blood pressure ${ }^{5,6}$, structural vascular remodelling ${ }^{7-9}$, altered vascular reactivity ${ }^{10,11}$, and atherosclerosis progression ${ }^{12-14}$. However, some studies showed no effect of $\mathrm{IH}$ on vascular parameters (for example ${ }^{15-18}$ ) and there was heterogeneity regarding effect size. Inconsistency between studies might be explained by disparity in rodent models and variations in patterns of IH exposure. Indeed, studies included mice or rats, predominantly males, but from different strains, of different ages and weights at baseline, and on different diets (standard versus high fat diet). There were also variations regarding the studied vascular beds, from large elastic to small muscular arteries, which might potentially account for substantial variability. Last but not least, IH patterns differed across studies. Animals were exposed to $\mathrm{IH}$ severities ranging from 5 to $10 \% \mathrm{FiO}_{2}$, hypoxic phases varied from 6 to 12 hours per day, and desaturation-reoxygenation sequences lasted from 20 seconds to a few minutes with the total duration of $\mathrm{IH}$ exposure ranging from a few days to up to several weeks or months.

With the goal of clarifying and strengthening our knowledge, we carried out a systematic review and meta-analysis addressing the overall impact of $\mathrm{IH}$ on vascular parameters, namely blood pressure, vascular remodeling, arterial function and atherosclerotic lesions in systemic arteries. Subgroup analyses and meta-regressions were performed to identify the main factors accounting for 
heterogeneity in results, with particular interest in assessing different rodent models and IH cycle characteristics.

\section{Methods}

The protocol for the meta-analysis was recorded in the PROSPERO registry under the number CRD42020169940 (https://www.crd.york.ac.uk/prospero/display_record.php?ID=CRD42020169940) . Owing to the very large amount of available data, this work focuses on structural and functional vascular outcomes.

\section{Search methods and study selection}

We searched MEDLINE for articles published up to January 31st, 2020. The search terms were "Intermittent hypoxia" AND "Rodent" OR "mice" OR "rat" (see PROSPERO record for exact query). We also searched for keywords and MeSH related to each search term. After the initial electronic search, we screened the titles and the abstracts to retrieve relevant articles. Eligibility was considered if they were written in English and addressed vascular outcomes of intermittent hypoxia in rodents. Then, the full manuscripts were screened for inclusion and exclusion criteria. The final inclusion of a study was made by one author, and independently confirmed by a second author.

We included only controlled studies with a well-established control group i.e. normoxic animals, for adult rodents exposed to chronic intermittent hypoxia. An intermittent hypoxia cycle was defined as the repetitive occurrence of several hypoxia-reoxygenation sequences during the same day. Chronic IH was defined as a repetition of IH cycles over time, for a minimum of one day. All wild-type rodent models (mouse and rat, male and female, young or aged, lean or obese) with exposure to intermittent hypoxia and compared to a normoxic group were included.

The outcomes considered as mandatory for inclusion were variables allowing characterization of vascular structure or function. This included blood pressure (systolic (SBP)/diastolic (DBP)/mean/pulsed), arterial reactivity (vasodilatory response to $10^{-6} \mathrm{M}$ acetylcholine and vasoconstriction responses to $10^{-6} \mathrm{M}$ phenylephrine or $10^{-8} \mathrm{M}$ endothelin-1, both ex vivo in cannulated vessels or vessel rings); vascular remodeling (Intima-Media Thickness (IMT), internal vessel diameter), and atherosclerosis plaque size in apolipoprotein E knock-out (ApoE-/-) mice.

We excluded studies without any control group (normoxic and untreated mice), studies in which hypoxia was applied continuously (i.e. no hypoxia-normoxia cycles), or studies in which hypoxia was combined with hypercapnic or hypobaric conditions. We also excluded studies using $\mathrm{IH}$ exposure in prenatal or perinatal periods and studies using transgenic animals, except for ApoE -/- mice that are 
the model of choice to study atherosclerosis plaques. Studies on pulmonary or cerebral vascular beds were also excluded.

\section{Assessment of methodological quality}

The quality assessment of studies was performed using the SYRCLE tool described by Hooijmans et al. ${ }^{19}$. This contains several types of bias: selection bias (sequence generation, baseline characteristics, and allocation concealment), performance bias (randomized housing of animals, blinding of investigators), detection bias (random outcome assessment, blinding of outcome assessor), attrition bias (incomplete outcome data), and reporting bias (selective outcome reporting). Each risk of bias was scored as High, Low, or Unclear. Three authors were involved and every discrepancy was discussed to achieve a shared decision.

\section{Statistical analysis}

We performed two separate meta-analyses for wild-type rodents and ApoE-/- mice. For each outcome, data were abstracted and analyzed using standardized mean difference, SMD $=((\mathrm{Mc}-\mathrm{Me})) / \mathrm{SD}$, where $\mathrm{Mc}$ is the mean of the outcome measure in the control group, Me is the mean of the outcome measure in the experimental group, and SD is the pooled standard deviation of the two groups. ${ }^{20}$ A SMD $>0.8$ was considered as large, 0.5-0.8 as moderate, and 0.2-0.5 small ${ }^{21}$. In case of a missing SD we calculated or estimated it from confidence intervals, standard errors, $\mathrm{t}$ values, $\mathrm{P}$ values or $\mathrm{F}$ values. ${ }^{22}$ The remaining SD were imputed using the mean outcome-specific SD from other included studies. All results are represented using orchard plots, an innovative data visualization tool well adapted for displaying the results of a large number of outcomes ${ }^{23}$ (supplementary figure 1 ).

To facilitate interpretation of homogeneous and widely used outcomes we performed meta-analyses using natural mean differences for arterial pressure outcomes and we back-transformed some SMD to natural mean differences using the median SD from the control groups of included studies using the target unit ${ }^{24}$. SMD are expressed with $95 \%$ confidence intervals. For study descriptions, we used medians and interquartile ranges (IQR).

Given the high anticipated heterogeneity in included studies we performed random effect metaanalysis by the restricted maximum-likelihood estimator method. ${ }^{25}$ Moreover, to account for correlation among multi-arm studies we constructed a hierarchical/mixed effect model with a random intercept for study. We explored sources of heterogeneity through pre-specified subgroup analyses and meta-regressions according to population (species, strain, sex, age, diet and body weight), year of 
publication and details of intermittent hypoxia protocols (oxygen fraction $\left(\mathrm{FiO}_{2}\right)$ during hypoxic phases, duration of hypoxic and normoxic phases, frequency, duration per day and total duration of exposure).

Given the large number of studied outcomes, we performed meta-regressions only on pre-specified primary outcomes: mean arterial blood pressure (MAP), intima-media thickness, response of vessel rings to acetylcholine, and atherosclerosis lesion size in ApoE-/- mice. We first performed univariate meta-regressions on study and animal characteristics (age and body weight were adjusted on species). Then, we added the significant predictors $(p<0.2)$ in meta-regression models evaluating intermittent hypoxia $(\mathrm{IH})$ protocol parameters. Given the exploratory nature of these analyses we considered all pvalues $<0.05$ as significant. Lastly, to assess the robustness of the findings, we performed sensitivity analyses by excluding potential outliers for significant meta-regressions.

Funnel plot asymmetry was also explored for primary outcomes using Egger's regression test, as recommended by the Cochrane handbook for systemic reviews of interventions ${ }^{26}$, with $p<0.1$ suggesting publication bias. We also performed a Trim and Fill analysis to assess the impact of small study effects on the meta-analyses results ${ }^{27}$.

All statistical analyses were performed using R statistical software (version 3.6.2). 


\section{Results}

Our literature review yielded 1886 references among which we ultimately selected 104 studies for inclusion in the meta-analysis, 92 concerning wild-type rodents and 12 using ApoE-/- mice (Figure 1). Supplementary table 1 and supplementary figure 2 present vascular outcomes available across the studies, settings of hypoxic exposure and experimental designs.

Among the 92 studies on wild-type rodents, 21 were performed in mice ( 20 in C57BI/6 mice, 1 in $129 \mathrm{~S} 1$ mice) and 71 in rats (50 in Sprague-Dawley, 18 in Wistar and 3 in other strains of rats). At study inclusion, median body weight and age were 26.5g (IQR 22.0-27.2) and 8.25 (7-10.5) weeks for mice and 275g (200-325) and 9 (8-13) weeks for rats respectively. Males were used in 83 studies, females in 4 studies, both males and females in one study, and 4 studies did not report the sex of the animals. Animals received standard diet in 76 studies and both standard and high-fat diet in 4 studies; diet was not specified in 12 studies.

For the studies on ApoE-/- mice, median weight was $27 \mathrm{~g}$ (27.9-29.5) and median age was 13 (8- 14.25) weeks. Eight studies used males, 3 used both males and females and 1 did not report the sex. The diet was standard in 5 studies, high fat in 5 studies and both standard and high fat in 2 studies.

Concerning IH protocols (Supplementary figure 2), median and IQ values of $\mathrm{FiO}_{2}$ during hypoxic periods were of 5\% (IQR 5-9), desaturation during 40 (30-90) seconds followed by 90 (30-232.5) seconds of reoxygenation and return to $\mathrm{FiO}_{2}$ of $21 \%$ (normoxia). Cycles were repeated on average for $8 \mathrm{~h} /$ day for a median duration of 21 (10-35) days. Forty two percent of studies used a $\mathrm{FiO}_{2}$ of 5\%, 10\% used a $\mathrm{FiO}_{2}$ of $6 \%$, and $20 \%$ used a $\mathrm{FiO}_{2}$ of $10 \%$ during hypoxic phases. Fifteen percent of studies had a duration of 7 days, $18 \%$ a duration of 14 days, $12 \%$ a duration of 21 days, $10 \%$ a duration of 28 days and $12 \%$ a duration of 35 days.

The number of included studies for each outcome is shown in supplementary table 1. Outcomes were excluded from statistical analysis when $<3$ studies reported them. In wild-type animals, this was the case for pulsed arterial pressure, atherosclerotic plaques, endothelial permeability, vasoconstriction in cannulated vessels, compliance/pulse wave velocity. In ApoE-/- mice, this was the case for all outcomes except for lesion size. 


\section{Impact of IH on arterial blood pressure}

Intermittent hypoxia significantly increased systolic, diastolic and mean arterial pressure in systemic vessels of wild-type rodents (Figure 2A-C). Mean arterial pressure (MAP) SMD was 1.33, $\mathrm{Cl}$ [1.07-1.59], $R^{2}=74.79 \%$ corresponding to a mean increase of $13.77 \mathrm{mmHg}(\mathrm{CI}[11.73 ; 15.82])$ after IH. Similarly, SBP increased by $13.73[11.08 ; 16.37] \mathrm{mmHg}$, and DBP by $12.72[9.03 ; 16.54] \mathrm{mmHg}$. Forest plots for SBP, DBP and MAP expressed in mmHg are shown in Supplementary Figure 3A, B, C.

Subgroup analyses showed a significant heterogeneity according to strain (test for subgroup difference <0.01): MAP increased in mice ( $\mathrm{C} 57 \mathrm{BI} / 6)$ as well as in rats (Wistar and Sprague Dawley) but not in Fischer 344, Wistar Kyoto or lean Zucker rats, although the number of studies was very limited for these strains (supplementary figure 4 and supplementary table 2). Meta-regression analyses for $\mathbf{I H}$ parameters after adjustment for significant confounders in univariate meta-regression (strain and year of publication) showed that a lower $\mathrm{FiO}_{2}$ during hypoxic phases was significantly associated with a higher MAP $(p=0.02)$ (Figure $2 D$ and supplementary table 2). Total duration of exposure was significantly associated with MAP but this association disappeared after exclusion of outlier studies $(p=0.13$, supplementary table 2$)$.

\section{Impact of IH on arterial reactivity}

Vasodilation tests, assessed on cannulated arteries as well as on arterial rings, showed that reactivity to Ach $\left(10^{-6} \mathrm{M}\right)$ significantly decreased after $\mathrm{IH}$ in both cannulated arteries $\mathrm{SMD}=-1.26[-2.10 ;-0.41], I^{2}$ $=62.1 \%$ (Figure $3 \mathrm{~A}$ ), and arterial rings SMD=-2.37 [-3.72;-1.02], $I^{2}=89.68 \%$ (Figure 3B). $\mathrm{IH}$ also increased vasoconstriction due to endothelin-1 $\left(10^{-8} \mathrm{M}\right)\left(\mathrm{SMD}=1.11[0.22 ; 2.01], l^{2}=41.82 \%\right)$ (Figure $\left.3 \mathrm{C}\right)$. On the other hand, there was no impact of $\mathrm{IH}$ on the vasoconstriction induced by phenylephrine $\left(10^{-6} \mathrm{M}\right)$ (SMD=0.04 [-0.6; 0.68], $I^{2}=41.82 \%$ ) (Figure 3D).

Subgroup analyses showed that the $\mathrm{IH}$-induced decrease in Ach-dependent vasodilation was observed in male but not in female rodents (SMD $0.12[-1.82 ; 2.06]$ in females vs $-2.22[-3.53 ; 0.9]$ in males, $\mathrm{p}<0.01$ ) (supplementary figure 5 ). Meta-regression analyses for $\mathrm{IH}$ parameters after adjustment for the significant confounder in univariate meta-regression (sex) showed that $\mathrm{FiO}_{2}$ was significantly associated with vasodilation impairment, especially at moderate hypoxia levels (i.e. in the range of $10 \% \mathrm{FiO}_{2}$ ) (Figure 3E and supplementary table 2). However, after adjusting for the duration of hypoxia exposure, this association did not persist $(p=0.27)$.

\section{Impact of IH on vascular remodeling}


In wild-type rodents, intima-media thickness significantly increased after IH (SMD 1.05 [0.52; 1.58], $I^{2}$ $=76.4 \%)$ (Figure 4A) with an increase of IMT of $3.23(1.61-5.00) \mu \mathrm{m}$. In contrast, inner vessel diameter did not significantly change after IH (Figure 4B). Subgroup analyses for IMT showed a much stronger effect of $\mathrm{IH}$ in mice (SMD $1.29[0.44 ; 2.14])$ than in rats (SMD $0.40[-0.13 ; 0.93])(p=0.05$ for subgroup difference) (supplementary figure 6). Univariate analysis also showed that age was negatively associated with IMT thickening ( $p=0.02$, Figure $4 C$ and supplementary table 2 ). Metaregression analysis for $\mathrm{IH}$ parameters after adjustment for significant predictors in univariate metaregression (strain, species, year of publication and age) were not significant for IMT at a p-value of 0.05 , but total duration of exposure tended to be associated with IMT thickening ( $p=0.07$ ) (Figure 4D and supplementary table 2).

\section{Impact of IH on atherosclerosis lesions in ApoE-/- mice}

Since vascular remodeling is an early step in the process of atherogenesis and because wild-type C57BI/6 mice are resistant to atherosclerosis, we included ApoE-/- mice in the meta-analysis, as a recognized model of susceptibility to atherosclerosis. The analysis showed that $\mathrm{IH}$ strongly increased atheromatous lesion size in ApoE-/- mice (SMD 1.1 [0.82; 1.41], $1^{2}=27.3 \%$ ) (Figure 5). Meta-regression analysis for $\mathrm{IH}$ parameters showed that $\mathrm{IH}$ parameters were not significantly associated with lesion size in ApoE-/- mice, except for a strong trend towards significance regarding the animal's body weight $(p=0.06)$ (supplementary table 2$)$.

\section{Risk of bias of studies}

The risk of bias of studies was assessed using the SYRCLE tool ${ }^{19}$. The results are presented in Supplementary Figure 7 and supplementary table 3. Items for which the risk of bias was low were selective outcome reporting (selection bias, 31\% low risk), sequence generation (39\% of studies are at low risk), baseline characteristics (43\% low risk) and incomplete outcome data (attrition bias, $58 \%$ low risk). However, incomplete outcome data was also the criterion with the highest percentage of highrisk studies (20\%). Finally, several outcomes, mainly categorized as performance and detection bias, were almost never mentioned and therefore scored as "unclear risk": allocation concealment, randomized housing, blinding of investigators, random outcome assessment, blinding of outcome assessor.

\section{Small study effect}


Funnel plots are presented in supplementary figure 8 for MAP, ring dilation, IMT and plaque size. For these four items, the asymmetric distribution of studies and a significant Egger regression test indicating a clear small study effect were observed. However, the SMD remained significant for all outcomes after correcting for missing studies (Trim and Fill analysis), meaning a consistent effect of IH on the outcomes (Supplementary Table 4).

\section{Discussion}

One of the main features of obstructive sleep apnea syndrome is intermittent hypoxia which represents the major trigger for cardiovascular complications ${ }^{28}$. A large corpus of studies in animals report diverse effect sizes for the impact of intermittent hypoxia on vascular parameters such as arterial pressure, altered vascular reactivity or remodeling. However, there is heterogeneity or even inconsistencies among the published results and, to date, no meta-analysis has been done to assess the impact of IH on these specific parameters. Our meta-analysis firmly establishes that intermittent hypoxia, in the absence of the confounders flawing human studies, triggers blood pressure elevation, alterations in vasodilation and atherosclerosis. Some of these responses were proportional to the hypoxic burden and duration of exposure. Another lesson was to delineate the different responses depending on the species, strains, sex and age of exposed animals.

\section{Impact of IH on vascular parameters}

Our meta-analysis confirmed that $\mathrm{IH}$ has a clear and significant impact on the primary outcomes: arterial pressure, vessel reactivity, intima-media thickness and atherosclerotic lesions (standard mean differences always >0.7). This is consistent with the known vascular effects of OSAS ${ }^{3,28}$, supporting the relevance of these $\mathrm{IH}$ models in rodents to the human pathology. In particular, while clinical studies are often difficult to interpret due to comorbidities, rodent studies suggest that $\mathrm{IH}$ per se may be the main cause of the vascular consequences of OSA.

Our meta-analysis showed that $\mathrm{IH}$ is associated with a significant increase in MAP, which is consistent with the elevation in sympathetic activity and blood pressure occurring in healthy volunteers submitted to 14 nights of intermittent hypoxia ${ }^{29}$. Interestingly, meta-regression analyses showed that $\mathrm{FiO}_{2}$ (i.e. the hypoxic burden) was associated with MAP, suggesting that the severity of hypoxia could be the key element for increased risk of hypertension. This is of high clinical significance since epidemiological studies ${ }^{30,31}$ already suggest a dose response relationship between OSA severity, as defined by the Apnea-Hypopnea Index, and hypertension. Also, responses to continuous positive airway pressure, the primary therapy for OSA, is related to the severity of hypoxia at the time of OSA 
diagnosis (see meta-analyses ${ }^{32,33}$ ). This suggests that beyond confounders (such as obesity or metabolic syndrome) IH may be the main parameter accounting for increased blood pressure in OSA. It also suggests that parameters such as minimal oxygen saturation or time spent at $<90 \%$ oxygen saturation should be used to describe more precisely OSA severity and hypoxic burden, rather than the AHI which does not necessarily reflect the patient's hypoxic burden.

In vascular reactivity studies, we observed that IH significantly altered endothelium-dependent vasodilation in response to acetylcholine. This is in line with studies in humans suggesting that OSA alters endothelial function ${ }^{34}$, and is associated with arterial stiffness $s^{35,36}$. Our group recently reported in an individual participant meta-analysis that among adults without overt CV disease, severe OSA (AHI 230) was independently associated with an increased risk of endothelial dysfunction that may predispose to late $\mathrm{CV}$ events ${ }^{37}$. Moreover, vasoconstriction in response to endothelin-1 was enhanced, while vasoconstriction in response to phenylephrine was not altered by $\mathrm{IH}$. Other vasoconstrictors, such as angiotensin II, have only been sparsely studied and the lack of data did not allow a metaanalysis. Interestingly, endothelin-1-induced vasoconstriction was largely studied with IH protocols that included $5 \% \mathrm{CO}_{2}$ in the air breathed by animals. $\mathrm{IH}$ combined with hypercapnia also increased the contractile response to ET-138,39. Our meta-analysis thus suggests that IH, rather than hypercapnia, may thus be responsible for the ET-1 response.

In this meta-analysis, we did not have sufficient statistical power to allow comparison of the reactivity of different vascular beds after $\mathrm{IH}$. However, some studies report some differences in the reactivity among vascular beds, in particular in small muscular vs large elastic arteries ${ }^{39}$. More studies are needed to allow a meta-analysis on the effects on various vascular beds.

$\mathrm{IH}$-induced vascular remodeling in rodents, as characterized by an augmentation in the intima-media thickness, is consistent with what is observed in humans ${ }^{40,41}$. Our results are also consistent with a recent meta-analysis limited to aorta IMT in mice ${ }^{42}$. Although not reaching significance $(p=0.07)$, the IMT tended to be associated with the total duration of exposure. This suggests a progressive remodeling of arteries over time. Interestingly, internal vessel diameter was not modified in rodents while, in humans, it is postulated that obstructive sleep apnea could induce an increase in diameter, at least in some patients and vessels ${ }^{43,44}$. IH models in rodents might rapidly attain the late characteristics of the disease such as thickening the media following changes in the inner diameter of vessels. Other remodeling parameters, such as compliance or elasticity, could not be included in our meta-analysis due to insufficient studies. However, IH in rodents is known to induce disorganization of the elastin fiber network ${ }^{8,45,46}$, reduced vessel distension and increased stiffness ${ }^{47,48}$. Taken together, 
IH induces structural remodeling along with alterations in vasoreactivity (blunted vasodilation and increased vasoconstriction) that could act synergistically to increase blood pressure.

Since increased IMT suggests ongoing atherogenesis in wild-type rodents, we included ApoE-/- mice in the meta-analysis because they are susceptible to atherosclerosis and a model of choice to study the impact of $\mathrm{IH}$ on atherosclerotic lesions. As expected, we found that $\mathrm{IH}$ strongly increased atherosclerotic lesions, consistent with the remodeling observed in wild-type animals ${ }^{8}$, and with the known pro-atherogenic consequences of OSAS in humans ${ }^{49,50}$. Interestingly, diet (standard vs high fat) did not significantly modulate plaque size after $\mathrm{IH}$, suggesting that $\mathrm{IH}$ is a robust inducer of plaques, independent of a high fat diet.

We performed meta-regression analyses to determine whether the variability of $\mathrm{IH}$ protocols could modulate the impact of $\mathrm{IH}$. Apart from the associations mentioned above, other meta-regressions found no significant effect of IH parameters on the selected vascular outcomes. This would suggest that IH has a robust impact on these outcomes, whatever the duration or severity of $\mathrm{IH}$ (in the range of our inclusion criteria). Interestingly, $\mathrm{FiO}_{2}$ was always $\leq 10 \%$ in the included studies, corresponding to the very severe hypoxia that occurs in the most severe OSAS patients. A less severe hypoxic burden has been little investigated in animal experiment designs. This needs investigation in future animal studies because the impact of OSA treatments in reducing cardiovascular consequences is mostly debated for the mild to moderate spectrum of the disease.

\section{Contribution of animal characteristics to IH impact}

In univariate analyses, we investigated the contribution of strain, sex, age, diet, body weight and year of publication on IH effects. The species and/or the strain significantly impacted MAP and IMT, suggesting that the choice of species/strain of mice or rats is important when designing a study. MAP is consistently elevated in the most frequently used models such as C57BI/6 mice, or Sprague-Dawley or Wistar rats. However, MAP was not found to be elevated in Fischer, Wistar kyoto or lean Zucker rats; although the very small number of studies using these strains probably accounts for this absence of statistical effect. Vascular remodeling as assessed by IMT is much more pronounced in mice than in rats; rats may thus not be a good model to study remodeling. Our meta-analysis may help researchers to choose the most appropriate models according to the objectives of their study.

Analysis by sex showed that the alteration of vessel dilation induced by $\mathrm{IH}$ is found in males, but not in females, despite the small number of studies using females $(n=5)$, suggesting a robust difference in the impact of $\mathrm{IH}$ on vasodilation between males and females. This may reflect a sex-related sensibility 
to the IH stimulus regarding this particular outcome, consistent with the known stimulation of endothelial-dependent vasodilation by oestrogens ${ }^{51}$. It may underlie the fact that, although most OSAS patients are men, specific studies of the vascular consequences of OSAS in women are necessary, although they are under-represented in the current literature ${ }^{35,52}$.

Animal age was inversely associated with $\mathrm{IH}$-induced intima-media thickening, suggesting that young animals may be more sensitive to IH in terms of vascular remodeling. This is consistent with data in humans ${ }^{33}$. Age had no significant association with other parameters. However, the vast majority of studies were performed in young animals (8-9 weeks old) and the very few using animals older than 50 weeks had to be considered as outliers. There is a lack of information about the effects of IH in older animals, indicating a need for further studies, particularly as obstructive sleep apnea is predominant in humans aged over 50 and not in young adults.

\section{Risk of bias and limitations of the analysis}

Funnel plots and Egger regression tests evidenced a small study effect for all the outcomes studied. Such an effect could have multiple reasons: selective reporting of results or publication bias, poor methodological quality of small studies leading to overestimation of results, true heterogeneity in the results or chance ${ }^{53}$. However, interestingly the SMD remained stable for the four main outcomes after the Trim and Fill analyses correcting for missing values, suggesting a limited impact of the small study effect on the results. A publication bias is not unusual in animal studies and is probably mainly due to selective reporting such as non-publication of negative results and selection of publishable outcomes. This could be associated with the frequent reluctance of journals to publish negative results. To avoid this reporting bias, we suggest that journals accept to publish animal study protocols, as is done for clinical studies, as well as negative results. For many of the listed items the risk of bias assessed with the SYRCLE risk of bias tool was quite high. This is in line with the poor SYRCLE scores in many other animal study meta-analyses. We argue for improvement of research and publication practices with regard to laboratory animal studies and the widespread adoption and implementation of the SYRCLE guidelines.

Another limitation of this meta-analysis was the heterogeneity of the outcomes and units of measurement. The use of SMD was intended to deal with this, but our analyses still showed strong heterogeneity for most of the outcomes studied. Statistical analyses only partly succeeded in identifying factors that could explain this heterogeneity, although some characteristics such as species, sex or certain IH properties were suggested. There may be other underlying factors that could 
potentially explain the heterogeneity of results that were not investigated in our study, such as laboratory-, experimentation- or investigator-dependent effects.

\section{Conclusion}

To our knowledge, this is the first meta-analysis of animal studies on the vascular impact of intermittent hypoxia. The meta-analysis based on a large corpus of articles evidenced the clear impact of $\mathrm{IH}$ on arterial pressure, reactivity and vascular remodeling. We identified some features of $\mathrm{IH}$, in particular $\mathrm{FiO}_{2}$ during hypoxia, which were sometimes associated with an amplified impact of $\mathrm{IH}$. However, in most cases the impact of $\mathrm{IH}$ was independent of the precise pattern of IH exposure, suggesting that whatever its modality, aimed at mimicking obstructive sleep apnea in humans, IH had a robust effect on rodent vessel structure and function.

\section{Figure legends}

\section{Figure 1: Flow diagram of the study}

Figure 2: IH increases blood pressure in systemic vessels of wild-type animals. Orchard plots showing SMD for: A) systolic blood pressure (SBP), B) diastolic blood pressure (DBP), C) mean arterial pressure (MAP). D) Significant association between $\mathrm{MAP}$ and $\mathrm{FiO}_{2}$ in meta-regression analysis $(\mathrm{p}=0.02$, slope= 0.13).

Figure 3: IH alters vasodilation with Acetylcholine and increases vasoconstriction with ET-1 but not vasoconstriction with Phenylephrine. Orchard plots showing SMD for A) cannulated artery dilation, B) artery ring dilation with Acetylcholine $\left.\left(10^{-6} \mathrm{M}\right), \mathrm{C}\right)$ artery ring constriction with Endothelin-1 $\left.\left(10^{-8} \mathrm{M}\right), \mathrm{D}\right)$ artery ring constriction with Phenylephrine $\left(10^{-6} \mathrm{M}\right)$. E) Association between ring vasodilation and $\mathrm{FiO}_{2}$ $(p<0.01$, slope $=-0.67)$.

Figure 4: IH provokes vascular structural remodeling. Orchard plots showing SMD for A) intima-media thickness (IMT) of systemic vessels, B) vessel luminal diameter. C) Univariate meta-regressions showing the negative correlation between IMT and rodent age $(p=0.02$, slope $=-0.03)$. D) Univariate adjusted meta-regression showing a strong tendency toward positive correlation between IMT and total duration of exposure in days $(p=0.07$, slope $=0.03)$. 
Figure 5: IH increases atherosclerotic plaque size in ApoE-/- mice. Orchard plot showing SMD for atherosclerosis lesion size.

\section{Funding}

This work was supported by the "Fondation du Souffle / Fondation pour la recherché en santé respiratoire" (PhD grant for O.H.), Fondation de l'avenir, Fondation Agir Pour les Maladies Chroniques, and ANR Arterylastic grant ANR-18-CE-18-0001 (PhD grant for Q.B.).

\section{Acknowledgments}

The authors thank Axel Couturier for helpful discussions and Alison Foote for critical reading and English editing. 


\section{References}

1. Benjafield, A. V. et al. Estimation of the global prevalence and burden of obstructive sleep apnoea: a literature-based analysis. Lancet Respir. Med. 7, 687-698 (2019).

2. Lévy, P. et al. Obstructive sleep apnoea syndrome. Nat. Rev. Dis. Primer 1, 15015 (2015).

3. Ryan, S. Mechanisms of cardiovascular disease in obstructive sleep apnoea. J. Thorac. Dis. 10, S4201-S4211 (2018).

4. Javaheri, S. et al. Sleep Apnea: Types, Mechanisms, and Clinical Cardiovascular Consequences. J. Am. Coll. Cardiol. 69, 841-858 (2017).

5. Dematteis, M. et al. Cardiovascular consequences of sleep-disordered breathing: contribution of animal models to understanding the human disease. ILAR J. 50, 262-281 (2009).

6. Fletcher, E. C., Lesske, J., Culman, J., Miller, C. C. \& Unger, T. Sympathetic denervation blocks blood pressure elevation in episodic hypoxia. Hypertens. Dallas Tex 1979 20, 612-619 (1992).

7. Yang, R. et al. Restoring leptin signaling reduces hyperlipidemia and improves vascular stiffness induced by chronic intermittent hypoxia. Am. J. Physiol. Heart Circ. Physiol. 300, H1467-1476 (2011).

8. Arnaud, C. et al. The inflammatory preatherosclerotic remodeling induced by intermittent hypoxia is attenuated by RANTES/CCL5 inhibition. Am. J. Respir. Crit. Care Med. 184, 724-731 (2011).

9. Gras, E. et al. Endothelin-1 mediates intermittent hypoxia-induced inflammatory vascular remodeling through HIF-1 activation. J. Appl. Physiol. Bethesda Md 1985 120, 437-443 (2016).

10. Totoson, P. et al. Atorvastatin protects against deleterious cardiovascular consequences induced by chronic intermittent hypoxia. Exp. Biol. Med. Maywood NJ 238, 223-232 (2013).

11. Phillips, S. A., Olson, E. B., Morgan, B. J. \& Lombard, J. H. Chronic intermittent hypoxia impairs endothelium-dependent dilation in rat cerebral and skeletal muscle resistance arteries. Am. J. Physiol. Heart Circ. Physiol. 286, H388-393 (2004).

12. Savransky, V. et al. Dyslipidemia and atherosclerosis induced by chronic intermittent hypoxia are attenuated by deficiency of stearoyl coenzyme A desaturase. Circ. Res. 103, 1173-1180 (2008). 
13. Arnaud, C., Poulain, L., Lévy, P. \& Dematteis, M. Inflammation contributes to the atherogenic role of intermittent hypoxia in apolipoprotein-E knock out mice. Atherosclerosis $\mathbf{2 1 9}, 425-431$ (2011).

14. Drager, L. F. et al. Chronic intermittent hypoxia induces atherosclerosis via activation of adipose angiopoietin-like 4. Am. J. Respir. Crit. Care Med. 188, 240-248 (2013).

15. Lee, M. Y. K. et al. Low but not high frequency of intermittent hypoxia suppresses endothelium-dependent, oxidative stress-mediated contractions in carotid arteries of obese mice. J. Appl. Physiol. Bethesda Md 1985 125, 1384-1395 (2018).

16. Lefebvre, B. et al. Functional assessment of vascular reactivity after chronic intermittent hypoxia in the rat. Respir. Physiol. Neurobiol. 150, 278-286 (2006).

17. Tuleta, I. et al. Hypoxia-induced endothelial dysfunction in apolipoprotein E-deficient mice; effects of infliximab and L-glutathione. Atherosclerosis 236, 400-410 (2014).

18. Zhou, S. et al. Deletion of metallothionein exacerbates intermittent hypoxia-induced oxidative and inflammatory injury in aorta. Oxid. Med. Cell. Longev. 2014, 141053 (2014).

19. Hooijmans, C. R. et al. SYRCLE's risk of bias tool for animal studies. BMC Med. Res. Methodol. 14,43 (2014).

20. Cohen, J. Statistical Power Analysis for the Behavioral Sciences. (Routledge, 1988).

21. Carson, C. The effective use of effect size indices in institutional research. Citováno Dne 11, 2016 (2012).

22. Higgins, J. \& Green, S. (editors). Cochrane Handbook for Systematic Reviews of Interventions.Version 5.1.0 [updated March 2011]. The Cochrane Collaboration. http://handbook.cochrane.org/ (2011).

23. The orchard plot: Cultivating a forest plot for use in ecology, evolution, and beyond Nakagawa - - Research Synthesis Methods - Wiley Online Library. https://onlinelibrary.wiley.com/doi/abs/10.1002/jrsm.1424. 
24. Murad, M. H., Wang, Z., Chu, H. \& Lin, L. When continuous outcomes are measured using different scales: guide for meta-analysis and interpretation. BMJ 364, k4817 (2019).

25. Viechtbauer, W. \& others. Conducting meta-analyses in R with the metafor package. J Stat Softw 36, 1-48 (2010).

26. Higgins, J. et al. Cochrane Handbook for Systematic Reviews of Interventions version 6.1 (updated September 2020). in Available from www.training.cochrane.org/handbook. (Cochrane, 2020).

27. Duval, S. \& Tweedie, R. Trim and Fill: A Simple Funnel-Plot-Based Method of Testing and Adjusting for Publication Bias in Meta-Analysis. Biometrics 56, 455-463 (2000).

28. Lévy, P. et al. Obstructive sleep apnoea syndrome. Nat. Rev. Dis. Primer 1, 15015 (2015).

29. Tamisier, R. et al. 14 nights of intermittent hypoxia elevate daytime blood pressure and sympathetic activity in healthy humans. Eur. Respir. J. 37, 119-128 (2011).

30. Peppard, P. E., Young, T., Palta, M. \& Skatrud, J. Prospective study of the association between sleep-disordered breathing and hypertension. N. Engl. J. Med. 342, 1378-1384 (2000).

31. Young, T. et al. Population-based study of sleep-disordered breathing as a risk factor for hypertension. Arch. Intern. Med. 157, 1746-1752 (1997).

32. Bratton, D. J., Gaisl, T., Wons, A. M. \& Kohler, M. CPAP vs Mandibular Advancement Devices and Blood Pressure in Patients With Obstructive Sleep Apnea: A Systematic Review and Metaanalysis. JAMA 314, 2280-2293 (2015).

33. Pengo, M. F. et al. Obstructive sleep apnoea treatment and blood pressure: which phenotypes predict a response? A systematic review and meta-analysis. Eur. Respir. J. 55, (2020).

34. Wang, Y. et al. Patients with Obstructive Sleep Apnea Display Decreased Flow-Mediated Dilatation: Evidence from a Meta-Analysis. Med. Sci. Monit. Int. Med. J. Exp. Clin. Res. 23, 10691082 (2017). 
35. Jenner, R. et al. Association of obstructive sleep apnea with arterial stiffness and nondipping blood pressure in patients with hypertension. J. Clin. Hypertens. Greenwich Conn 19, 910-918 (2017).

36. Joyeux-Faure, M. et al. Contribution of obstructive sleep apnoea to arterial stiffness: a metaanalysis using individual patient data. Thorax 73, 1146-1151 (2018).

37. Bironneau, V. et al. Sleep apnoea and endothelial dysfunction: An individual patient data meta-analysis. Sleep Med. Rev. 52, 101309 (2020).

38. Allahdadi, K. J., Walker, B. R. \& Kanagy, N. L. Augmented endothelin vasoconstriction in intermittent hypoxia-induced hypertension. Hypertens. Dallas Tex 1979 45, 705-709 (2005).

39. Allahdadi, K. J., Walker, B. R. \& Kanagy, N. L. ROK contribution to endothelin-mediated contraction in aorta and mesenteric arteries following intermittent hypoxia/hypercapnia in rats. Am. J. Physiol. Heart Circ. Physiol. 293, H2911-2918 (2007).

40. Nadeem, R. et al. Patients with obstructive sleep apnea display increased carotid intima media: a meta-analysis. Int. J. Vasc. Med. 2013, 839582 (2013).

41. Zhou, M. et al. The Association Between Obstructive Sleep Apnea and Carotid Intima-Media Thickness: A Systematic Review and Meta-Analysis. Angiology 68, 575-583 (2017).

42. Umeda, A. et al. Effects of Normoxic Recovery on Intima-Media Thickness of Aorta and Pulmonary Artery Following Intermittent Hypoxia in Mice. Front. Physiol. 11, (2020).

43. Tachikawa, R. et al. Impact of obstructive sleep apnea on abdominal aortic diameters. Am. J. Cardiol. 114, 618-623 (2014).

44. Kwon, Y. et al. Obstructive sleep apnea and structural/functional properties of the thoracic ascending aorta: The Multi-Ethnic Study of Atherosclerosis (MESA). Cardiology 142, 180-188 (2019).

45. Castro-Grattoni, A. L. et al. Intermittent Hypoxia-Induced Cardiovascular Remodeling Is Reversed by Normoxia in a Mouse Model of Sleep Apnea. Chest 149, 1400-1408 (2016). 
46. Rubies, C. et al. Aortic remodelling induced by obstructive apneas is normalized with mesenchymal stem cells infusion. Sci. Rep. 9, 11443 (2019).

47. Phillips, S. A., Olson, E. B., Lombard, J. H. \& Morgan, B. J. Chronic intermittent hypoxia alters NE reactivity and mechanics of skeletal muscle resistance arteries. J. Appl. Physiol. Bethesda Md 1985 100, 1117-1123 (2006).

48. Arnaud, C. et al. Nonmuscle Myosin Light Chain Kinase: A Key Player in Intermittent HypoxiaInduced Vascular Alterations. J. Am. Heart Assoc. 7, (2018).

49. Zhao, Y. Y. et al. Associations Between Sleep Apnea and Subclinical Carotid Atherosclerosis: The Multi-Ethnic Study of Atherosclerosis. Stroke 50, 3340-3346 (2019).

50. Lévy, P. et al. Obstructive sleep apnea and atherosclerosis. Prog. Cardiovasc. Dis. 51, 400-410 (2009).

51. Miller, V. M. \& Duckles, S. P. VASCULAR ACTIONS OF ESTROGENS: FUNCTIONAL IMPLICATIONS. Pharmacol. Rev. 60, 210-241 (2008).

52. Cano-Pumarega, I. et al. Sleep Apnea and Hypertension: Are There Sex Differences? The Vitoria Sleep Cohort. Chest 152, 742-750 (2017).

53. Page, M. J., Sterne, J. A. C., Higgins, J. P. T. \& Egger, M. Investigating and dealing with publication bias and other reporting biases in meta-analyses of health research: A review. Res. Synth. Methods (2020) doi:10.1002/jrsm.1468. 
Our meta-analysis included rodents exposed to experimental intermittent hypoxia. We demonstrate that IH significantly increased blood pressure, altered vasodilation and increased vasoconstriction, increased intimamedia thickness and atherosclerosis plaques. Altogether, IH is responsible for structural and functional vascular alterations in obstructive sleep apnea. 
Flow diagram of the study

$221 \times 163 \mathrm{~mm}(150 \times 150 \mathrm{DPI})$ 

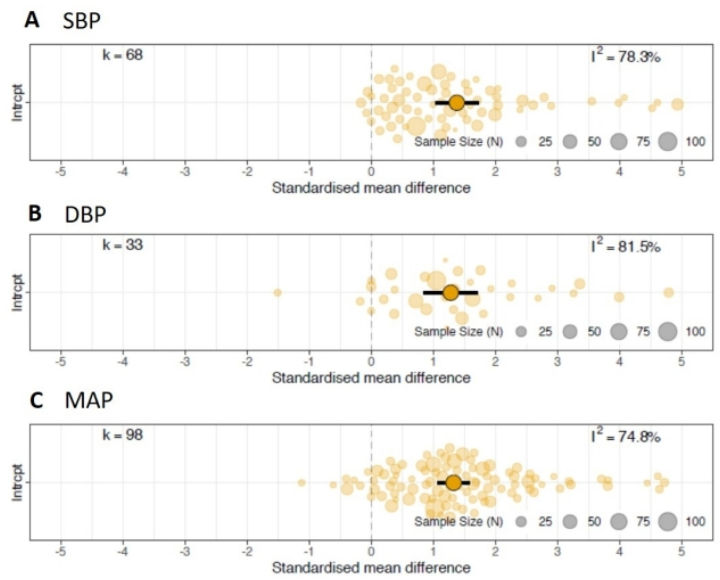

D

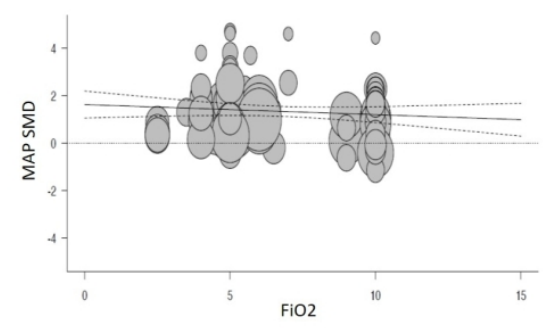

IH increases blood pressure in systemic vessels of wild-type animals. Orchard plots showing SMD for: A) systolic blood pressure (SBP), B) diastolic blood pressure (DBP), C) mean arterial pressure (MAP). D) Significant association between MAP and FiO2 in meta-regression analysis $(p=0.02$, slope $=-0.13)$.

$327 \times 149 \mathrm{~mm}(150 \times 150 \mathrm{DPI})$ 

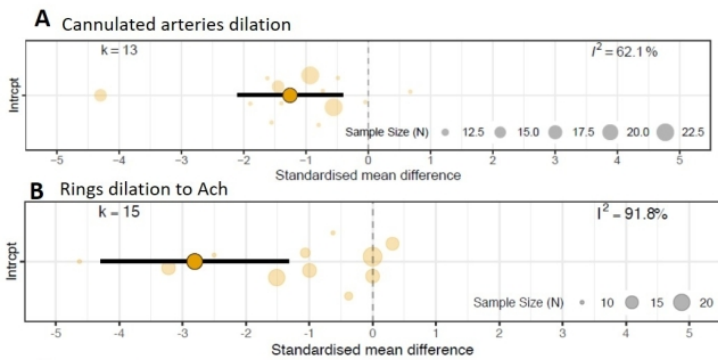

C Rings contraction to ET-1
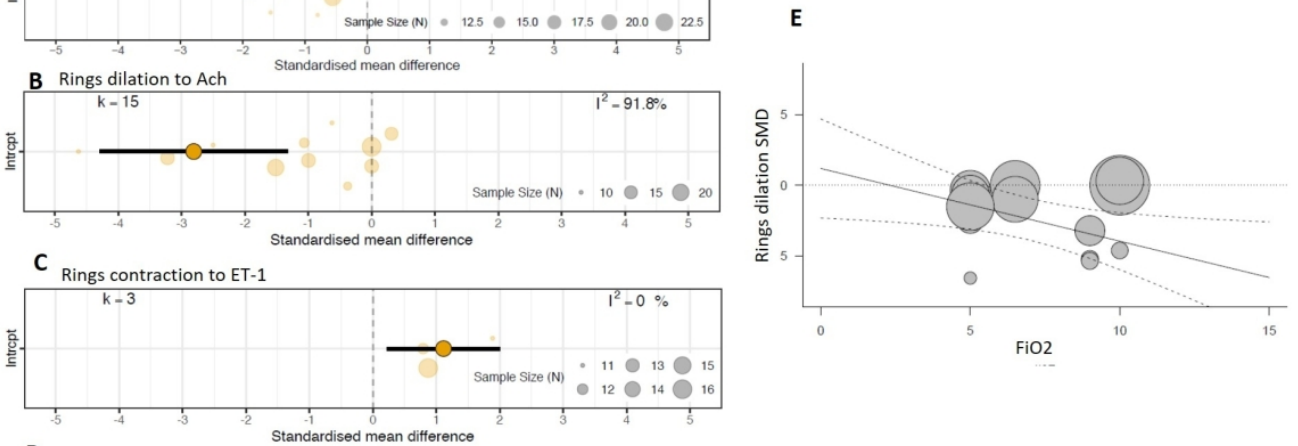

D Rings contraction to Phe

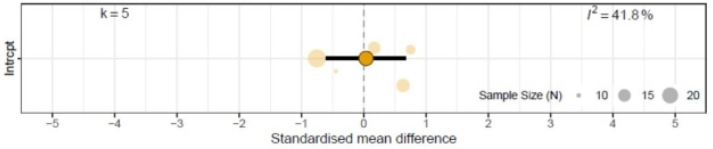

IH alters vasodilation with Acetylcholine and increases vasoconstriction with ET-1 but not vasoconstriction with Phenylephrine. Orchard plots showing SMD for A) cannulated artery dilation, B) artery ring dilation with Acetylcholine $(10-6 \mathrm{M}), \mathrm{C})$ artery ring constriction with Endothelin-1 (10-8M), D) artery ring constriction with Phenylephrine (10-6M). E) Association between ring vasodilation and FiO2 $(p<0.01$, slope $=-0.67)$. 

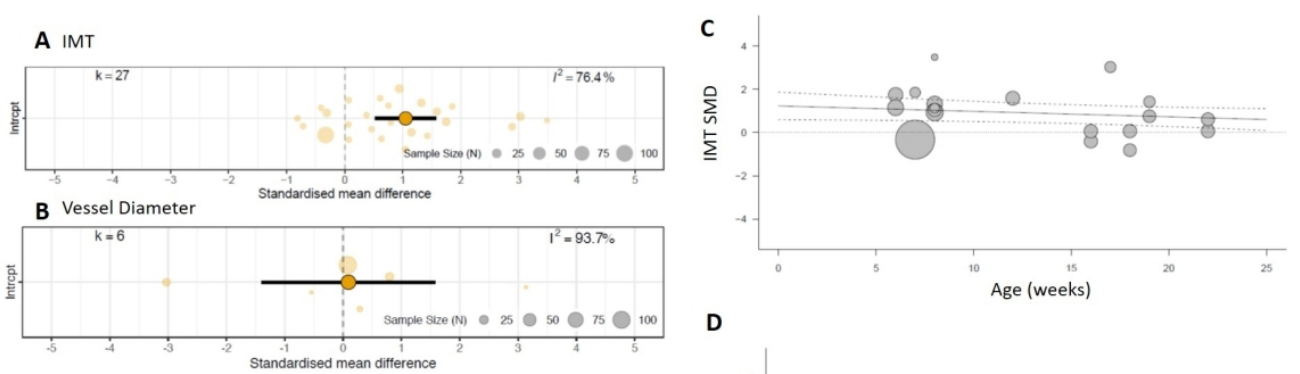

D

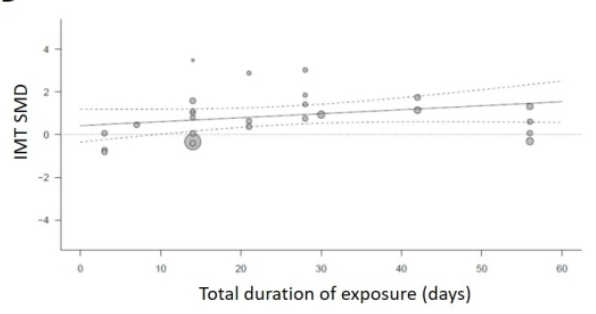

IH provokes vascular structural remodeling. Orchard plots showing SMD for A) intima-media thickness (IMT) of systemic vessels, B) vessel luminal diameter. C) Univariate meta-regressions showing the negative correlation between IMT and rodent age $(p=0.02$, slope $=-0.03)$. D) Univariate adjusted meta-regression showing a strong tendency toward positive correlation between IMT and total duration of exposure in days $(\mathrm{p}=0.07$, slope $=0.03)$.

$315 \times 156 \mathrm{~mm}(150 \times 150 \mathrm{DPI})$ 


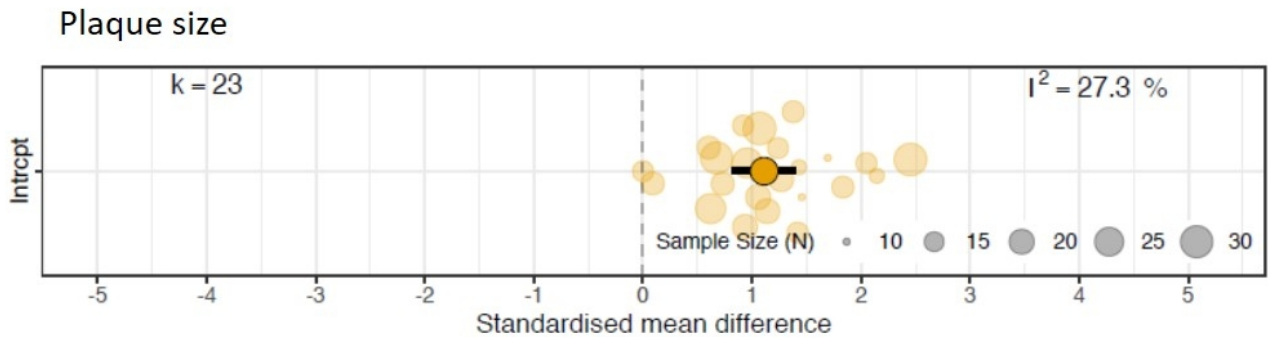

IH increases atherosclerotic plaque size in ApoE-/- mice. Orchard plot showing SMD for atherosclerosis lesion size.

$171 \times 47 \mathrm{~mm}(150 \times 150 \mathrm{DPI})$ 


\section{Supplemental data}

Supplementary Figure 1: Orchard plot example showing the meaning of the different parts of the plot.

Supplementary Figure 2: Description of the number of studies included depending on four $\mathrm{IH}$ parameters: A) $\mathrm{FiO}_{2}$ during hypoxic phase (in \%), B) Duration of each hypoxic phase (in seconds), C) Total duration of exposure (in days), D) Duration of IH exposure per day (in hours).

Supplementary Figure 3: Forest plots for Systolic Blood Pressure (A), Diastolic Blood Pressure (B) and Mean Arterial Pressure (C). Mean differences are expressed in $\mathrm{mmHg}$ with $95 \% \mathrm{Cl}$.

Supplementary Figure 4: Subgroup analysis for MAP according to the strain of wild-type animals. $p<0.01$ for subgroup differences.

Supplementary Figure 5: Subgroup analyses for vessel ring dilation according to the gender of rodents. $p<0.01$ for female vs male.

Supplementary Figure 6: Subgroup analysis for IMT according to the species of rodent. $p=0.05$ for mice vs rats.

Supplementary Figure 7: Risk of bias of studies assessed with the SYRCLE tool. For each item of the SYRCLE tool, the percentage of studies scored low/unclear/high risk of bias is shown.

Supplementary Figure 8: Funnel plots showing publication bias for the main outcomes: MAP (A), artery ring dilation (B), IMT (C), atherosclerosis lesions in ApoE-/- mice (D).

Supplementary Table 1: Description of studies included in the meta-analysis. Abbreviations: $n$ m non mentioned; $m$ male; f female; HF High Fat diet.

Due to its large size, this table could not be embedded in the text. See excel file 
Supplementary table 2: Meta-regression analyses for the main outcomes: MAP, dilation of artery rings, IMT, atherosclerosis lesions in ApoE-/- mice. Bold figures indicate significance at $p<0.05, ¥ p<0.2$ indicates moderators included in the multivariate model to adjust meta-regressions on $\mathrm{IH}$ parameters. $->$ represents the evolution before -> after exclusion of outlier studies.

\begin{tabular}{|c|c|c|c|c|c|c|c|c|c|c|c|c|}
\hline & \multicolumn{3}{|c|}{ MAP } & \multicolumn{3}{|c|}{ Arteries rings dilation } & \multicolumn{3}{|c|}{ IMT } & \multicolumn{3}{|c|}{ Atherosclerosis lesion } \\
\hline Moderator & $\mathrm{n}$ & slope & $\mathrm{p}$-val & $\mathrm{n}$ & slope & p-val & $\mathrm{n}$ & slope & $p$-val & $\mathrm{n}$ & slope & $\mathrm{p}$-val \\
\hline \multicolumn{13}{|c|}{ Univariate metaregressions } \\
\hline Strain & 96 & & $0.00 ¥$ & 14 & & 0.69 & 27 & & $0.09 ¥$ & 23 & & 0.78 \\
\hline Diet & 88 & & 0.39 & 14 & & 0.7 & NA & & & 23 & & 0.24 \\
\hline Species & 96 & & 0.28 & 14 & & 0.69 & 27 & & $0.05 ¥$ & 23 & & \\
\hline Gender & 94 & & 0.86 & 14 & & $0.00 ¥$ & 22 & & 0.89 & 22 & & 0.35 \\
\hline Body weight & 73 & 0.00 & 0.09 & 12 & 0.00 & 0.44 & 16 & 0.00 & 0.14 & 13 & -0.15 & 0.06 \\
\hline Year of publication & 96 & 0.04 & \begin{tabular}{|l|}
$0.02 ¥$ \\
\end{tabular} & 14 & -0.06 & 0.83 & 27 & 0.08 & $0.19 ¥$ & 23 & -0.02 & 0.64 \\
\hline Age & $38->36$ & $-0.01->0.02$ & $0.01->0.65$ & 10 & -0.06 & 0.84 & 20 & -0.03 & 0.02 & 18 & 0,00 & 0.96 \\
\hline \multicolumn{13}{|c|}{$\begin{array}{l}\text { Univariate adjusted metaregression } \\
\text { on } \mathrm{HI} \text { parameters }\end{array}$} \\
\hline $\mathrm{FiO}_{2}$ & 96 & -0.13 & 0.02 & 14 & -0.67 & 0.00 & 27 & 0.11 & 0.65 & 23 & 0.23 & 0.39 \\
\hline Duration of exposure & $96->93$ & $0.00->0.02$ & $0.02->0.12$ & 14 & 0.00 & 0.96 & 27 & 0.03 & 0.07 & 23 & 0.23 & 0.39 \\
\hline Duration of $\mathrm{IH}$ per day & 96 & -0.07 & 0.48 & 14 & 0.27 & 0.45 & 27 & -0.1 & 0.76 & 23 & 0.11 & 0.31 \\
\hline $\begin{array}{l}\text { Duration of } \\
\text { reoxygenation phase }\end{array}$ & 96 & 0,00 & 0.34 & 14 & 0,00 & 0.99 & 27 & 0.00 & 0.93 & 23 & -0.01 & 0.5 \\
\hline $\begin{array}{l}\text { Duration of hypoxic } \\
\text { phase }\end{array}$ & 96 & 0,00 & 0.53 & $14->13$ & $\begin{array}{c}-4.01->- \\
0.01\end{array}$ & $\begin{array}{c}0.04-> \\
0.80\end{array}$ & 27 & 0.00 & 0.69 & 23 & 0.00 & 0.7 \\
\hline
\end{tabular}


Supplementary Table 3: Risk of bias of studies, according to the 9 outcomes of the SYRCLE quality tool. L=Low, U= Unclear, H= High risk of bias.

Due to its large size, this table could not be embedded in the text. See excel file

Supplementary Table 4: Trim and Fill analysis for correction of small study effect. The table indicates the corrected SMD, confidence interval and $l^{2}$ after Trim and Fill analysis. All SMD remain significant after correction.

\begin{tabular}{|l|c|c|c|c|c|c|}
\cline { 2 - 7 } \multicolumn{1}{c|}{} & $\begin{array}{c}\text { Number of } \\
\text { missing studies }\end{array}$ & $\begin{array}{c}\text { Total number } \\
\text { of studies }\end{array}$ & SMD & Cl inf & Cl sup & $I^{2}$ \\
\hline MAP & 21 & 117 & 0.96 & 0.7 & 1.22 & $85 \%$ \\
\hline RVD & 1 & 15 & -1.77 & -2.93 & -0.61 & $91 \%$ \\
\hline IMT & 0 & 27 & 0.9 & 0.47 & 1.33 & $76 \%$ \\
\hline LESION & 6 & 29 & 0.89 & 0.61 & 1.16 & $50 \%$ \\
\hline
\end{tabular}




\begin{tabular}{|c|c|c|c|c|}
\hline Author & Journal & pmid & Year & Species \\
\hline Arnaud C & Am J Respir Crit Care Med. & 21680945 & 2011 & mouse \\
\hline Arnaud C & J Am Heart Assoc & 29371201 & 2018 & mouse \\
\hline Badran M & Oxid Med Cell Longev & 31093313 & 2019 & mouse \\
\hline Badran M & Sleep Med. & 24767726 & 2014 & mouse \\
\hline Campen MJ & J Appl Physiol & 16002771 & 2005 & mouse \\
\hline Castro-Grattoni AL & Chest & 26836908 & 2016 & mouse \\
\hline Castro-Grattoni-A & Respirology & 31215129 & 2020 & mouse \\
\hline Chen L & Cardiovasc pathol & 28985491 & 2017 & rat \\
\hline Chen YC & $\begin{array}{l}\text { Am J Physiol Regul Integr } \\
\text { Comp Physiol. }\end{array}$ & 27252472 & 2016 & rat \\
\hline Coleman CG & J Neurosci. & 20826673 & 2010 & mouse \\
\hline Cunningham JT & Hypertension. & 22689746 & 2012 & rat \\
\hline Del Rio R & Eur Respir J. & 22183481 & 2012 & rat \\
\hline Del Rio R & Eur Respir J. & 19996187 & 2010 & rat \\
\hline Dematteis M & Am J Respir Crit Care Med. & 17962641 & 2008 & mouse \\
\hline Diogo LN & Eur J Pharmacol. & 26291659 & 2015 & rat \\
\hline do Carmo JM & Acta Physiol (Oxf). & 30466186 & 2018 & rat \\
\hline Dopp JM & Respiration. & 21846958 & 2011 & rat \\
\hline Fenik VB & Front Neurol. & 22509173 & 2012 & rat \\
\hline Fletcher EC & J Appl Physiol & 1601808 & 1992 & rat \\
\hline Fletcher EC & Hypertension. & 1592450 & 1992 & rat \\
\hline González-Martín MC & Adv Exp Med Biol. & 19536495 & 2009 & rat \\
\hline Gras E & J Appl Physiol & 26679613 & 2016 & mouse \\
\hline Greenberg HE & J Appl Physiol & 9887143 & 1999 & rat \\
\hline Gu H & Am J Physiol Heart Circ Physiol. & 17693540 & 2007 & rat \\
\hline Guan P-A & J Cell Biochem. & 30259991 & 2018 & rat \\
\hline Guo QH & Clin Exp Pharmacol Physiol. & 23662699 & 2013 & rat \\
\hline Guo XL & Chin Med J & 24033945 & 2013 & rat \\
\hline Hayashi T & Am J Physiol Heart Circ Physiol. & 18326795 & 2008 & mouse \\
\hline Hernández-Guerra M & Hepatology. & 23174804 & 2013 & rat \\
\hline Hinojosa-Laborde C & Hypertension. & 16157795 & 2005 & rat \\
\hline Huang J & Respir Physiol Neurobiol. & 20227529 & 2010 & rat \\
\hline Huang J & Respir Physiol Neurobiol. & 19429526 & 2009 & rat \\
\hline Huang J & Respir Physiol Neurobiol. & 17442632 & 2007 & rat \\
\hline
\end{tabular}




\begin{tabular}{|c|c|c|c|c|}
\hline Hui AS & Hypertension. & 14597643 & 2003 & rat \\
\hline Hung MW & J Pineal Res. & 23869411 & 2013 & rat \\
\hline Iturriaga R & Adv Exp Med Biol. & 19536496 & 2009 & rat \\
\hline Iturriaga R & Adv Exp Med Biol. & 20217364 & 2010 & rat \\
\hline Kc P & J Physiol. & 20051497 & 2010 & rat \\
\hline Knight WD & $\begin{array}{c}\text { Am J Physiol Regul Integr } \\
\text { Comp Physiol. }\end{array}$ & 21543638 & 2011 & rat \\
\hline Krause BJ & Front Physiol. & 30087615 & 2018 & rat \\
\hline Krause BJ & J Hypertens & 25629363 & 2015 & rat \\
\hline Kumar GK & J Physiol. & 16777938 & 2006 & rat \\
\hline Kuo TB & Respir Physiol Neurobiol. & 20863915 & 2011 & rat \\
\hline Lai CJ & J Appl Physiol & 16484362 & 2006 & rat \\
\hline Lan XF & Sci Rep & 28871193 & 2017 & mouse \\
\hline Lee MYK-A & J Appl Physiol & 30091668 & 2018 & mouse \\
\hline Lefebvre B & Respir Physiol Neurobiol. & 15979951 & 2006 & rat \\
\hline Lesske J & J Hypertens. & 9488210 & 1997 & rat \\
\hline Li JR & plos one & 29641598 & 2018 & rat \\
\hline $\operatorname{Lin} M$ & Am J Physiol Heart Circ Physiol. & 17384123 & 2007 & mouse \\
\hline Liu $\mathrm{P}$ & J Cell Physiol. & 30609027 & 2019 & rat \\
\hline Lu W & sleep breath & 28078487 & 2017 & rat \\
\hline Lu W & Braz J Med Biol Res. & 28076452 & 2017 & rat \\
\hline Marcus NJ & Respir Physiol Neurobiol. & 22728949 & 2012 & rat \\
\hline Marcus NJ & Respir Physiol Neurobiol. & 19013546 & 2009 & rat \\
\hline Mentek M & Invest Ophthalmol Vis Sci. & 30383197 & 2018 & rat \\
\hline Moraes DJ & Hypertension & 27480839 & 2016 & rat \\
\hline Moreau JM & Brain Res. & 26183015 & 2015 & rat \\
\hline Moya EA & Oxid Med Cell Longev. & 26798430 & 2016 & rat \\
\hline Nanduri J & J Physiol. & 27506145 & 2016 & rat \\
\hline Olea $\mathrm{E}$ & J Appl Physiol & 25103975 & 2014 & rat \\
\hline Peng YJ & J Appl Physiol & 22016368 & 2012 & rat \\
\hline Perim RR & Exp Physiol. & 26195236 & 2015 & rat \\
\hline Philippi NR & Respir Physiol Neurobiol. & 19969108 & 2010 & rat \\
\hline Phillips SA & J Appl Physiol & 16357071 & 2006 & rat \\
\hline Phillips SA & Am J Physiol Heart Circ Physiol. & 14512283 & 2004 & rat \\
\hline Poulain L & Mediators Inflamm. & 25873766 & 2015 & mouse \\
\hline Prabha K & Adv Exp Med Biol. & 21445804 & 2011 & rat \\
\hline Quintero M & J Physiol. & 26752660 & 2016 & rat \\
\hline Raghuraman G & Antioxid Redox Signal. & 20836657 & 2011 & rat \\
\hline
\end{tabular}




\begin{tabular}{|c|c|c|c|c|}
\hline Ray AD & $\begin{array}{c}\text { Am J Physiol Regul Integr } \\
\text { Comp Physiol. }\end{array}$ & 17459910 & 2007 & rat \\
\hline Ren $\mathrm{H}$ & Mol Med Rep & 28983603 & 2017 & rat \\
\hline Ribon-Demars A & Acta Physiol (Oxf). & 29947475 & 2018 & rat \\
\hline Sacramento JF & Respir Physiol Neurobiol. & 26993367 & 2016 & rat \\
\hline Schulz R & J Hypertens. & 24270180 & 2014 & mouse \\
\hline Shang J & Chin Med J & 24033947 & 2013 & rat \\
\hline Sharpe AL & Am J Physiol Heart Circ Physiol. & 24097432 & 2013 & rat \\
\hline Shirai M & Basic Res Cardiol. & 25139633 & 2014 & rat \\
\hline Silva $\mathrm{AQ}$ & J Physiol. & 21242253 & 2011 & rat \\
\hline Souza GM & Exp Physiol. & 25631702 & 2015 & rat \\
\hline Suarez-Giron MC & Front Physiol. & 29881356 & 2018 & mouse \\
\hline Tahawi Z & J Appl Physiol & 11299297 & 2001 & rat \\
\hline Takahashi K & Sci Rep. & 30560943 & 2018 & mouse \\
\hline Wu JG & J Cell Physiol. & 29215742 & 2018 & rat \\
\hline Yamamoto K & Auton Neurosci. & 23167993 & 2013 & rat \\
\hline Yang & J Am Heart Assoc & 30757948 & 2019 & rat \\
\hline Yang $\mathrm{R}$ & Am J Physiol Heart Circ Physiol. & 21278136 & 2011 & mouse \\
\hline Zhang Y & $\begin{array}{l}\text { Biochem Biophys Res } \\
\text { Commun. }\end{array}$ & 28822761 & 2017 & mouse \\
\hline Zhou S & Oxid Med Cell Longev. & 25177426 & 2014 & mouse \\
\hline Zoccal DB & Auton Neurosci. & 17293169 & 2007 & rat \\
\hline Zoccal DB & Exp Physiol. & 17085676 & 2007 & rat \\
\hline
\end{tabular}

Number of studies per outcome

\begin{tabular}{|c|l|c|c|c|}
\hline ApoE-/- & \multicolumn{2}{|l|}{} \\
\hline Arnaud C & Atherosclerosis. & 21917260 & 2011 & souris \\
\hline Drager LF & Am J Respir Crit Care Med. & 23328524 & 2013 & souris \\
\hline Fang G & Am J Pathol. & 22940439 & 2012 & souris \\
\hline Gautier-Veyret E & pharmacol res & 29920371 & 2018 & souris \\
\hline Gautier-Veyret E & Eur Respir J. & 23060635 & 2013 & souris \\
\hline Kato R & Eur J Pharmacol. & 26276396 & 2015 & souris \\
\hline Li RC & Am J Respir Crit Care Med. & 21493735 & 2011 & souris \\
\hline Poulain L & Eur Respir J. & 24072212 & 2014 & souris \\
\hline Song D-A & Atherosclerosis & 29407890 & 2018 & souris \\
\hline Tuleta I & Atherosclerosis. & 25150938 & 2014 & souris \\
\hline Van Noolen L & Prostaglandins Leukot Essent & 25139400 & 2014 & souris \\
\hline Fatty Acids. & 29673358 & 2018 & souris \\
\hline
\end{tabular}


Number of studies per outcome

1
2
3
4
5
6
7
8
9
10
11
12
13
14
15
16
17
18
19
20
21
22
23
24
25
26
27
28
29
30
31
32
33
34
35
36
37
38
39
40
41
42
43
44
45
46
47
48
49
50
51
52
53
54
55
56
57
58
59
60

15 


\begin{tabular}{|c|c|c|c|c|c|c|}
\hline Strain & $\begin{array}{l}\text { Body weight } \\
\text { (grams) }\end{array}$ & Gender & Age & Diet & $\mathrm{FiO}_{2}(\%)$ & $\begin{array}{l}\text { Duration of } \\
\text { hypoxic phase } \\
\text { (seconds) }\end{array}$ \\
\hline C57BL/6 & $\mathrm{nm}$ & $\mathrm{m}$ & 8 & standard & 5 & 30 \\
\hline C57BL/6 & $\mathrm{nm}$ & $\mathrm{m}$ & 12 & standard & 5 & 30 \\
\hline C57BL/6 & 36 & $\mathrm{~m}$ & 10 & standard & 5 & 30 \\
\hline C57BL/6 & 26.5 & $\mathrm{~m}$ & 9 & standard + HF & 5 & 30 \\
\hline C57BL/6 & $\mathrm{nm}$ & $\mathrm{m}$ & 14 & standard & 5 & 30 \\
\hline C57BL/6 & $\mathrm{nm}$ & $\mathrm{m}$ & 6 & standard & 5 & 20 \\
\hline C57BL/6 & 21 and 24 & $f$ & 8 and 72 & standard & 5 & 20 \\
\hline sprague dawley & 195 & $\mathrm{~m}$ & adult & standard & 9 & 90 \\
\hline wistar & $\mathrm{nm}$ & $\mathrm{m}$ & 12 & standard & 5 & 90 \\
\hline C57BL/6 & 22 & $\mathrm{~m}$ & adult & standard & 10 & 90 \\
\hline sprague dawley & 300 & $\mathrm{~m}$ & $\mathrm{~nm}$ & standard & 10 & 180 \\
\hline sprague dawley & 220 & $\mathrm{~m}$ & $\mathrm{~nm}$ & standard & 5 & 20 \\
\hline sprague dawley & 200 & $\mathrm{~m}$ & $\mathrm{~nm}$ & standard & 5 & 20 \\
\hline C57BL/6 & 27.2 & $\mathrm{~m}$ & 8 & $\mathrm{~nm}$ & 4 & 30 \\
\hline wistar & 308.4 & $\mathrm{~m}$ & 9.5 & standard & 5 & 210 \\
\hline sprague dawley & $\mathrm{nm}$ & $\mathrm{m}$ & 13 & standard & 7 & 120 \\
\hline sprague dawley & 326 & $\mathrm{~m}$ & 12.4 & standard & 10 & 120 \\
\hline sprague dawley & 314.5 & $\mathrm{~m}$ & $\mathrm{~nm}$ & standard & 10 & 90 \\
\hline Wistar & 312.5 & $\mathrm{~m}$ & $\mathrm{~nm}$ & standard & 4 & 15 \\
\hline $\begin{array}{c}\text { wistar + sprague } \\
\text { dawley }\end{array}$ & 337.5 & $\mathrm{~m}$ & $\mathrm{~nm}$ & standard & 4 & 15 \\
\hline Wistar & 290 & $\mathrm{~m}$ & adult & standard & 10 & 40 \\
\hline C57BL/6 & $\mathrm{nm}$ & $\mathrm{nm}$ & 8 & standard & 5 & 30 \\
\hline sprague dawley & 175 & $\mathrm{~m}$ & 8 & standard & 7 & 30 \\
\hline Fischer 344 & $\mathrm{~nm}$ & $\mathrm{~nm}$ & 14 & $\mathrm{~nm}$ & 10 & 90 \\
\hline sprague dawley & 200 & $\mathrm{~m}$ & adult & standard & 9 & 90 \\
\hline sprague dawley & 195 & $M$ & $\mathrm{~nm}$ & standard & 9 & 60 \\
\hline wistar & 225 & M & 8 & standard & 10 & 160 \\
\hline $\mathrm{C} 57 \mathrm{BL} / 6$ & 21.6 & $\mathrm{~m}$ & 9.5 & $\mathrm{~nm}$ & 5 & 30 \\
\hline sprague dawley & 237.5 & $\mathrm{~m}$ & matched & standard & 9 & 120 \\
\hline sprague dawley & $\mathrm{nm}$ & $m$ and $f$ & adult & standard & 10 & 180 \\
\hline sprague dawley & 245 & $\mathrm{~m}$ & $\mathrm{~nm}$ & standard & 9 & 60 \\
\hline sprague dawley & 245 & $\mathrm{~m}$ & $\mathrm{~nm}$ & standard & 9 & 60 \\
\hline sprague dawley & 165 & $\mathrm{~m}$ & $\mathrm{~nm}$ & standard & 7.5 & 60 \\
\hline
\end{tabular}




\begin{tabular}{|c|c|c|c|c|c|c|}
\hline sprague dawley & 187.5 & $\mathrm{~m}$ & $\mathrm{~nm}$ & standard & 10 & 90 \\
\hline sprague dawley & $\mathrm{nm}$ & $M$ & 4 & standard & 5 & 30 \\
\hline sprague dawley & 225 & $\mathrm{~m}$ & $\mathrm{~nm}$ & $\mathrm{~nm}$ & 5 & 20 \\
\hline sprague dawley & 200 & $\mathrm{~m}$ & $\mathrm{~nm}$ & $\mathrm{~nm}$ & 5 & 20 \\
\hline sprague dawley & 327.5 & $\mathrm{~m}$ & $\mathrm{~nm}$ & standard & 10 & 45 \\
\hline sprague dawley & 300 & $\mathrm{~m}$ & adult & standard & 10 & 180 \\
\hline sprague dawley & 200 & $\mathrm{~m}$ & $\mathrm{~nm}$ & standard & 5.5 & 20 \\
\hline sprague dawley & 200 & $\mathrm{~m}$ & adult & standard & 5 & 20 \\
\hline sprague dawley & 275 & $\mathrm{~m}$ & adult & $\mathrm{nm}$ & 5 & 100 \\
\hline sprague dawley & 423 & $M$ & adult & standard & 4 & 30 \\
\hline sprague dawley & 472 & $\mathrm{~m}$ & adult & standard & 4 & 30 \\
\hline $\mathrm{C} 57 \mathrm{BL} / 6$ & $\mathrm{~nm}$ & $f$ & 7 & $\mathrm{~nm}$ & 5 & 10 \\
\hline C57BL/6 & 27 & $\mathrm{~m}$ & 4 & standard + HF & $5 / 10$ & 240 \\
\hline Wistar & 2230 & $\mathrm{~m}$ & adult & standard & 5 & 40 \\
\hline $\begin{array}{c}\text { wistar + sprague } \\
\text { dawley }\end{array}$ & 312.5 & $\mathrm{~m}$ & $\mathrm{~nm}$ & standard & 3.5 & 15 \\
\hline sprague dawley & 205 & $\mathrm{~m}$ & adult & standard & 9 & 90 \\
\hline C57BL/6 & $\mathrm{nm}$ & $\mathrm{nm}$ & 14 & $\mathrm{~nm}$ & 5.7 & 360 \\
\hline sprague dawley & 225 & $\mathrm{~m}$ & $\mathrm{~nm}$ & standard & 5 & 30 \\
\hline sprague dawley & 200 & $\mathrm{~m}$ & $\mathrm{~nm}$ & standard & 5 & 30 \\
\hline sprague dawley & 190 & $\mathrm{~m}$ & $\mathrm{~nm}$ & standard & 5 & 30 \\
\hline sprague dawley & 311 & $\mathrm{~m}$ & 13.5 & standard & 10 & 105 \\
\hline sprague dawley & $\mathrm{nm}$ & $\mathrm{m}$ & adult & standard & 10 & 105 \\
\hline wistar & 287 & $\mathrm{~m}$ & 7 & standard & 5 & 30 \\
\hline wistar & 110 & $\mathrm{~m}$ & $\mathrm{~nm}$ & $\mathrm{~nm}$ & 6 & 35 \\
\hline sprague dawley & 325 & $\mathrm{~m}$ & adult & standard & 6.5 & 80 \\
\hline sprague dawley & 200 & $\mathrm{~m}$ & adult & standard & 5 & 20 \\
\hline sprague dawley & 250 & $\mathrm{~m}$ & adult & standard & 5 & 15 \\
\hline wistar & 475 & $\mathrm{~m}$ & 24 & standard $+\mathrm{HF}$ & 5 & 40 \\
\hline sprague dawley & 250 & $\mathrm{~m}$ & $\mathrm{~nm}$ & standard & 5 & 100 \\
\hline wistar & 47.5 & $\mathrm{~m}$ & $\mathrm{~nm}$ & standard & 6 & 240 \\
\hline sprague dawley & 435 & $\mathrm{~m}$ & from 14 to 24 & standard & 10 & 120 \\
\hline sprague dawley & 325 & $\mathrm{~m}$ & matched & standard & 10 & 60 \\
\hline sprague dawley & 325 & $\mathrm{~m}$ & matched & standard & 10 & 60 \\
\hline C57BL/6 & $\mathrm{nm}$ & $\mathrm{m}$ & 17 & standard & 5 & 30 \\
\hline sprague dawley & 327.5 & $\mathrm{~m}$ & adult & standard & 5 & 15 \\
\hline wistar & 366.2 & $\mathrm{~m}$ & 14 and 92 & standard & 5 & 40 \\
\hline sprague dawley & 225 & $\mathrm{~m}$ & adult & standard & 5 & 15 \\
\hline
\end{tabular}




\begin{tabular}{|c|c|c|c|c|c|c|}
\hline Zucker (lean) & 479 & $\mathrm{~m}$ & 48 & standard & 4.5 & 90 \\
\hline wistar & 191 & $\mathrm{~m}$ & 9 & standard & 5 & 90 \\
\hline sprague dawley & 275 & $f$ & 9 & standard & 10 & 120 \\
\hline wistar & 360 & $\mathrm{~m}$ & 10.5 & standard & 5 & 210 \\
\hline C57BL/6 & $\mathrm{nm}$ & $\mathrm{m}$ & 8.5 & standard & 7 & 120 \\
\hline wistar & $\mathrm{nm}$ & $M$ & 8 & standard & 10 & 120 \\
\hline sprague dawley & 312.5 & M & $\mathrm{nm}$ & standard & 10 & 180 \\
\hline sprague dawley & 260 & $\mathrm{~m}$ & 9 & standard & 4 & 90 \\
\hline sprague dawley & 216 & $\mathrm{~m}$ & 8 & standard & 6 & 240 \\
\hline wistar & 242 & $f$ & 8.5 & standard & 6 & 40 \\
\hline C57BL/6 & $\mathrm{nm}$ & $\mathrm{m}$ & 6 & standard & 5 & 20 \\
\hline sprague dawley & 350 & $\mathrm{~m}$ & 13 & standard & 2.5 & 15 \\
\hline $\mathrm{C} 57 \mathrm{BL} / 6$ & $\mathrm{~nm}$ & $\mathrm{~m}$ & 8 & standard & 10 & 90 \\
\hline sprague dawley & 275 & $\mathrm{~m}$ & $\mathrm{~nm}$ & standard & 7.5 & 60 \\
\hline sprague dawley & 498 & $\mathrm{~m}$ & 14 & standard & 9 & 360 \\
\hline sprague dawley & 200 & $\mathrm{~m}$ & 9 & standard & 6 & 80 \\
\hline $\mathrm{C} 57 \mathrm{BL} / 6$ & 25 & $\mathrm{~m}$ & 10 & standard & 5 & 30 \\
\hline C57BL/6 & $\mathrm{nm}$ & $\mathrm{m}$ & 7 & standard + HF & 6.5 & 30 \\
\hline 129S1 & $\mathrm{nm}$ & $\mathrm{nm}$ & $\mathrm{nm}$ & standard & 8 & 60 \\
\hline wistar & 295 & $\mathrm{~m}$ & $\mathrm{~nm}$ & $\mathrm{~nm}$ & 6 & 240 \\
\hline wistar & 293 & $\mathrm{~m}$ & $\mathrm{~nm}$ & $\mathrm{~nm}$ & 6 & 240 \\
\hline
\end{tabular}

\begin{tabular}{|c|c|c|c|c|c|c|}
\hline ApoE -/- & 26.3 & $\mathrm{~m}$ & 15 & standard + HF & 5 & 30 \\
\hline ApoE -/- & 25.5 & $\mathrm{~m}$ & 12 & $\mathrm{HF}$ & 6.5 & 30 \\
\hline ApoE-/- & $\mathrm{nm}$ & $\mathrm{m}+\mathrm{f}$ & $\mathrm{nm}$ & standard & 6 & 30 \\
\hline ApoE -/- & 30 & $\mathrm{~m}$ & 14 & standard & 5 & 30 \\
\hline ApoE-/- & $\mathrm{nm}$ & $\mathrm{m}$ & 14 & standard & 5 & 30 \\
\hline ApoE -/- & $\mathrm{nm}$ & $\mathrm{m}$ & 8 & $\mathrm{HF}$ & 5 & 30 \\
\hline ApoE -/- & $\mathrm{nm}$ & $\mathrm{nm}$ & $\mathrm{nm}$ & $\mathrm{HF}$ & 5.7 & 90 \\
\hline ApoE -/- & 29 & $\mathrm{~m}$ & 20 & standard & 5 & 30 \\
\hline ApoE -/- & 27 & $\mathrm{~m}+\mathrm{f}$ & 7 & standard + HF & 6 & 30 \\
\hline ApoE -/- & $\mathrm{nm}$ & $\mathrm{m}+\mathrm{f}$ & 11 & $\mathrm{HF}$ & 5 & 60 \\
\hline ApoE -/- & $\mathrm{nm}$ & $\mathrm{m}$ & 14 & standard & 5 & 30 \\
\hline ApoE -/- & $\mathrm{nm}$ & $\mathrm{m}$ & 8 & HF & 6 & 10 \\
\hline
\end{tabular}



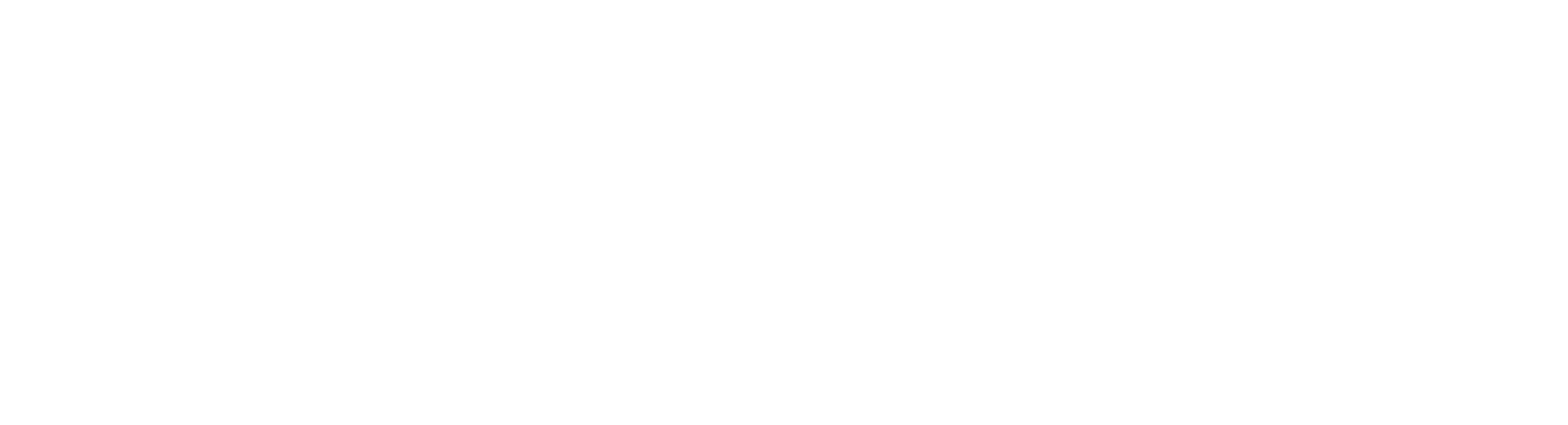

P




\begin{tabular}{|c|c|c|c|c|c|c|c|}
\hline $\begin{array}{c}\text { Duration of } \\
\text { reoxygenation } \\
\text { phase (seconds) }\end{array}$ & $\begin{array}{l}\text { Duration of } \\
\text { cycles per day } \\
\text { (hours) }\end{array}$ & $\begin{array}{l}\text { Total duration } \\
\text { of exposure } \\
\text { (days) }\end{array}$ & SBP & DBP & MAP & IMT & $\begin{array}{c}\text { inner vessel } \\
\text { diameter }\end{array}$ \\
\hline 30 & 8 & 14 & & & & $\bullet$ & $\bullet$ \\
\hline 30 & 8 & $7 / 14$ & $\bullet$ & & & $\bullet$ & \\
\hline 30 & 12 & 56 & & & & & \\
\hline 30 & 12 & 42 & & & & & \\
\hline 30 & 12 & 35 & & & $\bullet$ & & \\
\hline 40 & 6 & 42 & & & & $\bullet$ & \\
\hline 40 & 6 & 56 & & & & $\bullet$ & \\
\hline 90 & 8 & 7 / 14 / 21 & $\bullet$ & & & $\bullet$ & \\
\hline 90 & 8 & 28 & & & $\bullet$ & & \\
\hline 90 & 8 & 14 / 35 & $\bullet$ & & $\bullet$ & & \\
\hline 180 & 8 & 7 & & & $\bullet$ & & \\
\hline 280 & 8 & 21 & $\bullet$ & $\bullet$ & $\bullet$ & & \\
\hline 280 & 8 & 21 & & & $\bullet$ & & \\
\hline 30 & 8 & 14 & & & $\bullet$ & $\bullet$ & \\
\hline 420 & 10.5 & 35 & $\bullet$ & $\bullet$ & $\bullet$ & & \\
\hline 180 & 8 & 7 & & & $\bullet$ & & \\
\hline 120 & 12 & 14 & & & & & \\
\hline 90 & 10 & $7 / 21 / 35$ & $\bullet$ & & & & \\
\hline 15 & 7 & 35 & $\bullet$ & $\bullet$ & $\bullet$ & & \\
\hline 15 & 7 & 20 / 30 / 35 & $\bullet$ & $\bullet$ & $\bullet$ & & \\
\hline 80 & 8 & 15 & & & $\bullet$ & & \\
\hline 30 & 8 & 14 & & & & $\bullet$ & \\
\hline 30 & 8 & 30 & & & $\bullet$ & & \\
\hline 270 & 12 & 35 & & & $\bullet$ & & \\
\hline 90 & 8 & $7 / 21 / 35$ & $\bullet$ & $\bullet$ & & & \\
\hline 60 & 8 & / 9 / 12 / 15 / 21 & $\bullet$ & & & & \\
\hline 140 & 8 & 30 & & & $\bullet$ & • & $\bullet$ \\
\hline 30 & 8 & 10 & & & $\bullet$ & & \\
\hline 120 & 12 & 14 & & & $\bullet$ & & \\
\hline 180 & 8 & 7 & & & $\bullet$ & & \\
\hline 180 & 8 & 21 & & & $\bullet$ & & \\
\hline 180 & 8 & 21 & & & $\bullet$ & & \\
\hline 60 & 8 & 35 & $\bullet$ & $\bullet$ & & & \\
\hline
\end{tabular}




\begin{tabular}{|c|c|c|c|c|c|c|c|}
\hline 90 & 24 & $3 / 7$ / 14 / 30 & $\bullet$ & $\bullet$ & & & \\
\hline 30 & 8 & $7 / 14$ / 21 & - & & & & \\
\hline 280 & 8 & 21 & & & $\bullet$ & & \\
\hline 280 & 8 & $7 / 14$ / 21 & & & $\bullet$ & & \\
\hline 300 & 8 & 10 & & & - & & \\
\hline 180 & 8 & 7 & & & $\bullet$ & & \\
\hline 280 & 8 & 35 & & & $\bullet$ & & - \\
\hline 280 & 8 & 21 & $\bullet$ & $\bullet$ & $\bullet$ & $\bullet$ & $\bullet$ \\
\hline 300 & 8 & 10 & & & - & & \\
\hline 45 & 6 & 30 & & & $\bullet$ & & \\
\hline 45 & 6 & 7 / 14 / 30 & & & $\bullet$ & & \\
\hline 80 & 8 & 28 & & & & $\bullet$ & \\
\hline 120 & 8 & 28 & & & $\bullet$ & & \\
\hline 20 & 8 & 35 & & & - & & \\
\hline 15 & 7 & $20 / 30 / 35$ & & & $\bullet$ & & \\
\hline 90 & 8 & 21 & & & & & \\
\hline 360 & 12 & 90 & & & $\bullet$ & & \\
\hline 60 & 8 & 7 / 14 / 28 & $\bullet$ & $\bullet$ & $\bullet$ & & \\
\hline 60 & 8 & 7 / 14 / 21 & - & & & & \\
\hline 60 & 8 & $7 / 14$ / $21 / 28$ & $\bullet$ & & & & \\
\hline 135 & 12 & 28 & & & & & \\
\hline 135 & 12 & $1 / 7 / 14$ & & & $\bullet$ & & \\
\hline 30 & 8 & 14 & $\bullet$ & $\bullet$ & $\bullet$ & $\bullet$ & $\bullet$ \\
\hline 540 & 8 & 10 & & . & $\bullet$ & & \\
\hline 120 & 8 & $7 / 95$ & $\bullet$ & $\bullet$ & - & & \\
\hline 280 & 8 & 7 & $\bullet$ & $\bullet$ & & & \\
\hline 300 & 8 & Oct-30 & & & $\bullet$ & & \\
\hline 80 & 8 & 14 & & & $\bullet$ & & \\
\hline 300 & 8 & 14 & & & - & & \\
\hline 300 & 8 & 10 & $\bullet$ & $\bullet$ & $\bullet$ & & \\
\hline 120 & 12 & $3 / 14 / 28 / 56$ & & & & $\bullet$ & \\
\hline 240 & 12 & 14 & & & $\bullet$ & $\bullet$ & \\
\hline 240 & 12 & 14 & & & $\bullet$ & & $\bullet$ \\
\hline 30 & 8 & 28 & & & & $\bullet$ & \\
\hline 300 & 8 & 10 & & & $\bullet$ & & \\
\hline 80 & 8 & 14 & & & $\bullet$ & & \\
\hline 300 & 8 & 10 & - & - & - & & \\
\hline
\end{tabular}




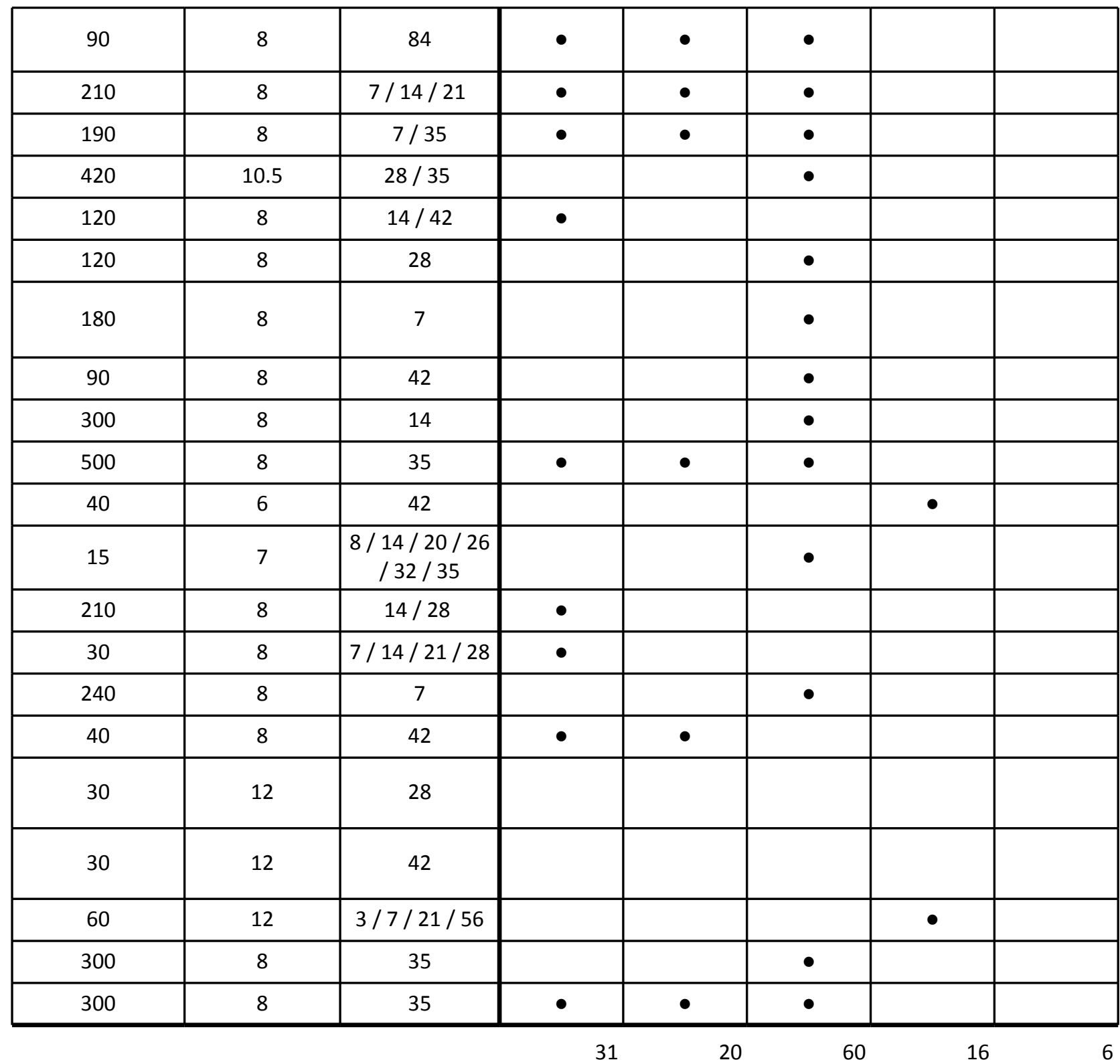

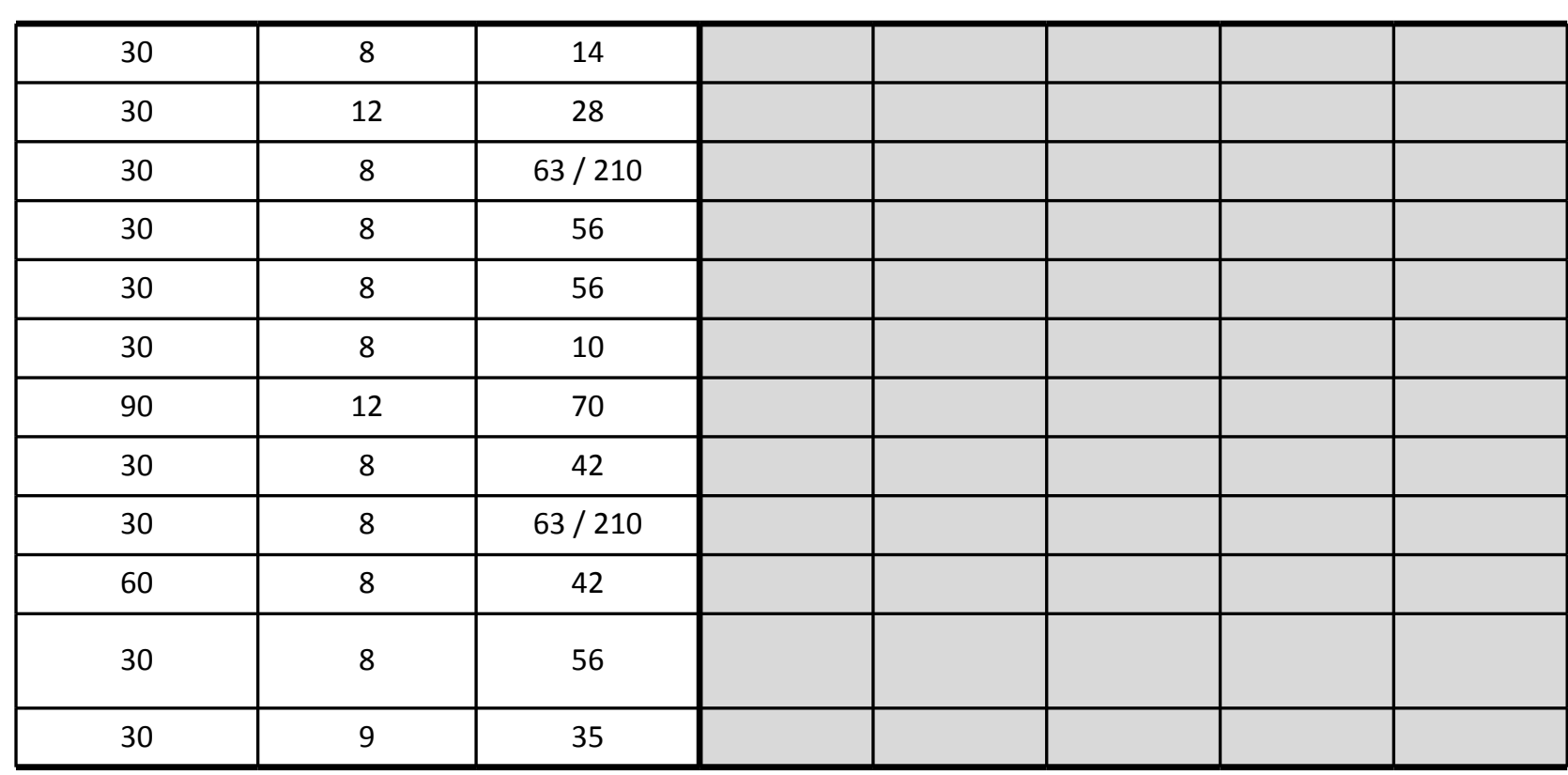




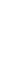

(7)

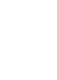

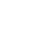

3

5

7

0

3.

6

.

8

4

4

46




\begin{tabular}{|c|c|c|c|}
\hline $\begin{array}{l}\text { cannulated } \\
\text { vessel } \\
\text { dilation }\end{array}$ & $\begin{array}{l}\text { vessel ring } \\
\text { contraction }\end{array}$ & $\begin{array}{l}\text { vessel ring } \\
\text { dilation }\end{array}$ & Lesion size \\
\hline & & & \\
\hline & & & \\
\hline & $\bullet$ & $\bullet$ & \\
\hline & & $\bullet$ & \\
\hline & & & \\
\hline & & & \\
\hline & & & \\
\hline & $\bullet$ & $\bullet$ & \\
\hline & & & \\
\hline & & & \\
\hline & & & \\
\hline & & & \\
\hline & & & \\
\hline & & & \\
\hline & & & \\
\hline & & & \\
\hline$\bullet$ & & & \\
\hline & & & \\
\hline & & & \\
\hline & & & \\
\hline & & & \\
\hline & & & \\
\hline & & & \\
\hline & & & \\
\hline & & $\bullet$ & \\
\hline & & & \\
\hline & & & \\
\hline & & & \\
\hline & & & \\
\hline & & & \\
\hline & & & \\
\hline & & & \\
\hline
\end{tabular}




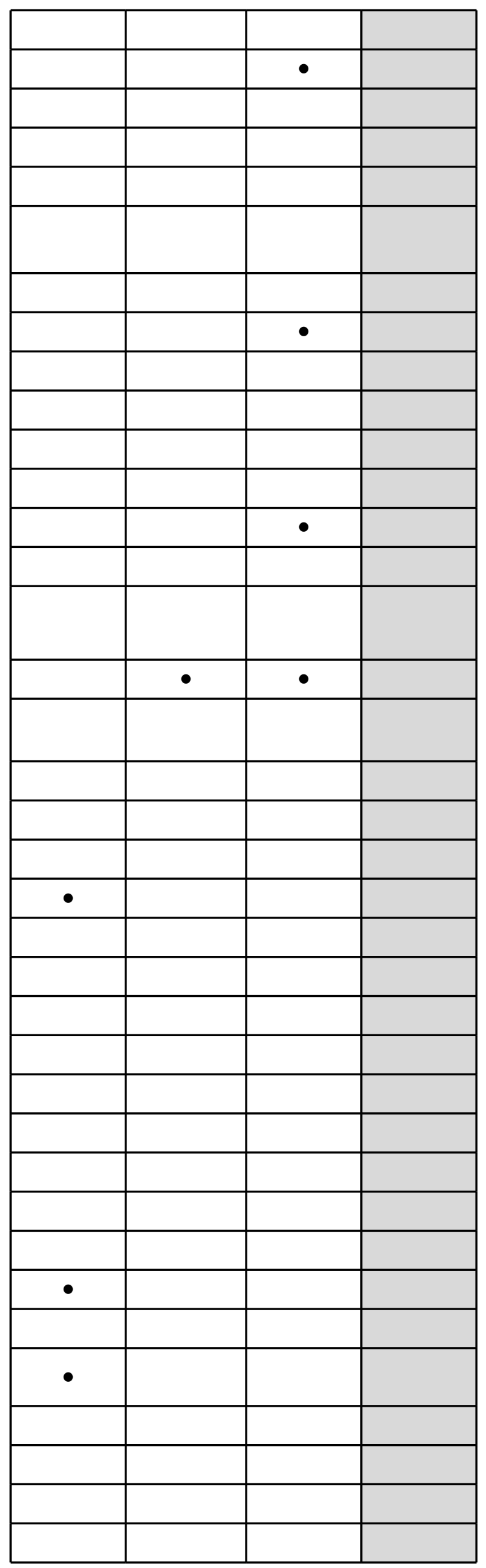



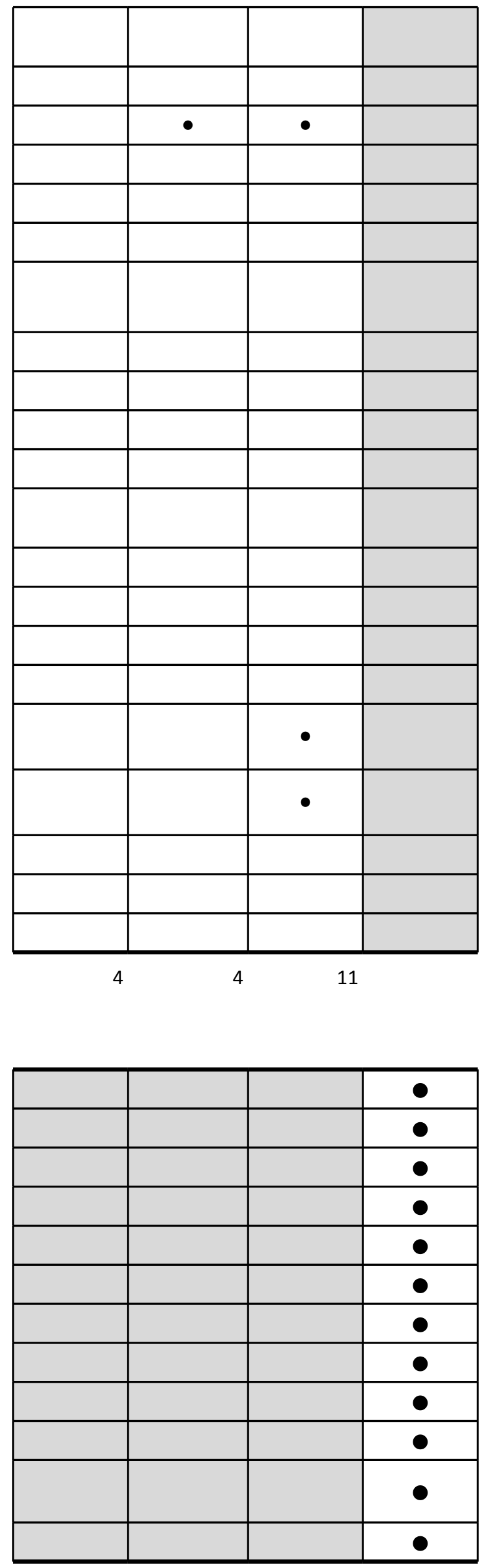


\begin{tabular}{|c|c|c|c|c|}
\hline Author & Journal & PMID & year & $\begin{array}{l}\text { Sequence } \\
\text { generation }\end{array}$ \\
\hline Arnaud C & J Am Heart Assoc & 29371201 & 2018 & $\mathbf{L}$ \\
\hline Arnaud C & Am J Respir Crit Care Med. & 21680945 & 2011 & $\mathbf{L}$ \\
\hline Badran M & Oxid Med Cell Longev & 31093313 & 2019 & $\mathbf{U}$ \\
\hline Badran M & Sleep Med. & 24767726 & 2014 & $\mathbf{U}$ \\
\hline Campen MJ & J Appl Physiol & 16002771 & 2005 & $\mathbf{U}$ \\
\hline Castro-Grattoni & Respirology & 31215129 & 2020 & $\mathbf{L}$ \\
\hline Castro-Grattoni AL & Chest & 26836908 & 2016 & $\mathbf{L}$ \\
\hline Chen L & Cardiovasc pathol & 28985491 & 2017 & $\mathbf{L}$ \\
\hline Chen YC & $\begin{array}{l}\text { Am J Physiol Regul Integr Comp } \\
\text { Physiol. }\end{array}$ & 27252472 & 2016 & $\mathbf{U}$ \\
\hline Coleman CG & J Neurosci. & 20826673 & 2010 & $\mathbf{L}$ \\
\hline Cunningham JT & Hypertension. & 22689746 & 2012 & $\mathbf{U}$ \\
\hline Del Rio R & Eur Respir J. & 22183481 & 2012 & $\mathbf{L}$ \\
\hline Del Rio R & Eur Respir J. & 19996187 & 2010 & $\mathbf{L}$ \\
\hline Dematteis M & Am J Respir Crit Care Med. & 17962641 & 2008 & $\mathbf{L}$ \\
\hline Diogo LN & Eur J Pharmacol. & 26291659 & 2015 & $\mathbf{L}$ \\
\hline do Carmo JM & Acta Physiol (Oxf). & 30466186 & 2018 & $\mathbf{U}$ \\
\hline Dopp JM & Respiration. & 21846958 & 2011 & $\mathbf{U}$ \\
\hline Fenik VB & Front Neurol. & 22509173 & 2012 & $\mathbf{U}$ \\
\hline Fletcher EC & Hypertension. & 1592450 & 1992 & $\mathbf{U}$ \\
\hline Fletcher EC & J Appl Physiol & 1601808 & 1992 & $\mathbf{U}$ \\
\hline González-Martín MC & Adv Exp Med Biol. & 19536495 & 2009 & $\mathbf{U}$ \\
\hline Gras E & J Appl Physiol & 26679613 & 2016 & $\mathbf{L}$ \\
\hline Greenberg HE & J Appl Physiol & 9887143 & 1999 & $\mathbf{U}$ \\
\hline $\mathrm{GuH}$ & Am J Physiol Heart Circ Physiol. & 17693540 & 2007 & $\mathbf{U}$ \\
\hline Guan P & J Cell Biochem. & 30259991 & 2018 & $\mathbf{L}$ \\
\hline Guo QH & Clin Exp Pharmacol Physiol. & 23662699 & 2013 & $\mathbf{L}$ \\
\hline Guo XL & Chin Med J & 24033945 & 2013 & $\mathbf{L}$ \\
\hline Hayashi T & Am J Physiol Heart Circ Physiol. & 18326795 & 2008 & $\mathbf{L}$ \\
\hline Hernández-Guerra M & Hepatology. & 23174804 & 2013 & $\mathbf{L}$ \\
\hline Hinojosa-Laborde C & Hypertension. & 16157795 & 2005 & $\mathbf{U}$ \\
\hline Huang J & Respir Physiol Neurobiol. & 20227529 & 2010 & $\mathbf{L}$ \\
\hline Huang J & Respir Physiol Neurobiol. & 19429526 & 2009 & $\mathbf{L}$ \\
\hline Huang J & Respir Physiol Neurobiol. & 17442632 & 2007 & $\mathbf{L}$ \\
\hline Hui AS & Hypertension. & 14597643 & 2003 & $\mathbf{U}$ \\
\hline Hung MW & J Pineal Res. & 23869411 & 2013 & $\mathbf{L}$ \\
\hline Iturriaga $\mathrm{R}$ & Adv Exp Med Biol. & 20217364 & 2010 & $\mathbf{H}$ \\
\hline Iturriaga R & Adv Exp Med Biol. & 19536496 & 2009 & $\mathbf{H}$ \\
\hline Kc P & J Physiol. & 20051497 & 2010 & $\mathbf{U}$ \\
\hline Knight WD & $\begin{array}{l}\text { Am J Physiol Regul Integr Comp } \\
\text { Physiol. }\end{array}$ & 21543638 & 2011 & $\mathbf{U}$ \\
\hline Krause BJ & Front Physiol. & 30087615 & 2018 & $\mathbf{U}$ \\
\hline Krause BJ & J Hypertens & 25629363 & 2015 & $\mathbf{L}$ \\
\hline Kumar GK & J Physiol. & 16777938 & 2006 & $\mathbf{U}$ \\
\hline
\end{tabular}




\begin{tabular}{|c|c|c|c|c|}
\hline Kuo TB & Respir Physiol Neurobiol. & 20863915 & 2011 & $\mathbf{L}$ \\
\hline Lai CJ & J Appl Physiol & 16484362 & 2006 & $\mathbf{U}$ \\
\hline Lan XF & Sci Rep & 28871193 & 2017 & $\mathbf{L}$ \\
\hline Lee MYK & J Appl Physiol & 30091668 & 2018 & $\mathbf{L}$ \\
\hline Lefebvre B & Respir Physiol Neurobiol. & 15979951 & 2006 & $\mathbf{U}$ \\
\hline Lesske J & J Hypertens. & 9488210 & 1997 & $\mathbf{U}$ \\
\hline Li JR & Plos one & 29641598 & 2018 & $\mathbf{L}$ \\
\hline $\operatorname{Lin} \mathrm{M}$ & Am J Physiol Heart Circ Physiol. & 17384123 & 2007 & $\mathbf{U}$ \\
\hline Liu $\mathrm{P}$ & J Cell Physiol. & 30609027 & 2019 & $\mathbf{L}$ \\
\hline Lu W & sleep breath & 28078487 & 2017 & $\mathbf{L}$ \\
\hline Lu W & Braz J Med Biol Res. & 28076452 & 2017 & $\mathbf{L}$ \\
\hline Marcus NJ & Respir Physiol Neurobiol. & 22728949 & 2012 & $\mathbf{U}$ \\
\hline Marcus NJ & Respir Physiol Neurobiol. & 19013546 & 2009 & $\mathbf{U}$ \\
\hline Mentek M & Invest Ophthalmol Vis Sci. & 30383197 & 2018 & $\mathbf{U}$ \\
\hline Moraes DJ & Hypertension & 27480839 & 2016 & $\mathbf{U}$ \\
\hline Moreau JM & Brain Res. & 26183015 & 2015 & $\mathbf{U}$ \\
\hline Moya EA & Oxid Med Cell Longev. & 26798430 & 2016 & $\mathbf{U}$ \\
\hline Nanduri J & J Physiol. & 27506145 & 2016 & $\mathbf{U}$ \\
\hline Olea $\mathrm{E}$ & J Appl Physiol & 25103975 & 2014 & $\mathbf{U}$ \\
\hline Peng YJ & J Appl Physiol & 22016368 & 2012 & $\mathbf{U}$ \\
\hline Perim RR & Exp Physiol. & 26195236 & 2015 & $\mathbf{U}$ \\
\hline Philippi NR & Respir Physiol Neurobiol. & 19969108 & 2010 & $\mathbf{U}$ \\
\hline Phillips SA & J Appl Physiol & 16357071 & 2006 & $\mathbf{L}$ \\
\hline Phillips SA & Am J Physiol Heart Circ Physiol. & 14512283 & 2004 & $\mathbf{U}$ \\
\hline Poulain L & Mediators Inflamm. & 25873766 & 2015 & $\mathbf{U}$ \\
\hline Prabha K & Adv Exp Med Biol. & 21445804 & 2011 & $\mathbf{U}$ \\
\hline Quintero M & J Physiol. & 26752660 & 2016 & $\mathbf{U}$ \\
\hline Raghuraman G & Antioxid Redox Signal. & 20836657 & 2011 & $\bar{U}$ \\
\hline Ray AD & $\begin{array}{c}\text { Am J Physiol Regul Integr Comp } \\
\text { Physiol. }\end{array}$ & 17459910 & 2007 & $\mathbf{U}$ \\
\hline Ren $\mathrm{H}$ & Mol Med Rep & 28983603 & 2017 & $\mathbf{L}$ \\
\hline Ribon-Demars A & Acta Physiol (Oxf). & 29947475 & 2018 & $\mathbf{U}$ \\
\hline Sacramento JF & Respir Physiol Neurobiol. & 26993367 & 2016 & $\bar{U}$ \\
\hline Schulz R & J Hypertens. & 24270180 & 2014 & $\mathbf{L}$ \\
\hline Shang J & Chin Med J & 24033947 & 2013 & $\mathbf{L}$ \\
\hline Sharpe AL & Am J Physiol Heart Circ Physiol. & 24097432 & 2013 & U \\
\hline Shirai M & Basic Res Cardiol. & 25139633 & 2014 & $\bar{U}$ \\
\hline Silva AQ & J Physiol. & 21242253 & 2011 & $\mathbf{U}$ \\
\hline Souza GM & Exp Physiol. & 25631702 & 2015 & $\mathbf{U}$ \\
\hline Suarez-Giron MC & Front Physiol. & 29881356 & 2018 & $\mathbf{L}$ \\
\hline Tahawi Z & J Appl Physiol & 11299297 & 2001 & $\bar{U}$ \\
\hline Takahashi K & Sci Rep. & 30560943 & 2018 & $\bar{U}$ \\
\hline Wu JG & J Cell Physiol. & 29215742 & 2018 & $\mathrm{~L}$ \\
\hline Yamamoto K & Auton Neurosci. & 23167993 & 2013 & $\mathbf{L}$ \\
\hline Yang & J Am Heart Assoc & 30757948 & 2019 & $\bar{L}$ \\
\hline Yang R & Am J Physiol Heart Circ Physiol. & 21278136 & 2011 & $\bar{U}$ \\
\hline Zhang Y & Biochem Biophys Res Commun. & 28822761 & 2017 & $\bar{U}$ \\
\hline Zhou S & Oxid Med Cell Longev. & 25177426 & 2014 & $\bar{U}$ \\
\hline Zoccal DB & Auton Neurosci. & 17293169 & 2007 & $\bar{U}$ \\
\hline Zoccal DB & Exp Physiol. & 17085676 & 2007 & $\bar{U}$ \\
\hline
\end{tabular}




\begin{tabular}{|c|c|c|c|c|}
\hline ApoE -/- studies & & & & \\
\hline Arnaud C & Atherosclerosis. & 21917260 & 2011 & U \\
\hline Drager LF & Am J Respir Crit Care Med. & 23328524 & 2013 & U \\
\hline Fang G & Am J Pathol. & 22940439 & 2012 & U \\
\hline Gautier-Veyret E & pharmacol res & 29920371 & 2018 & L \\
\hline Gautier-Veyret E & Eur Respir J. & 23060635 & 2013 & L \\
\hline Kato R & Eur J Pharmacol. & 26276396 & 2015 & U \\
\hline Li RC & Am J Respir Crit Care Med. & 21493735 & 2011 & U \\
\hline Poulain L & Eur Respir J. & 24072212 & 2014 & U \\
\hline Song D & Atherosclerosis & 29407890 & 2018 & L \\
\hline Tuleta I & Atherosclerosis. & 25150938 & 2014 & L \\
\hline Van Noolen L & Prostaglandins Leukot Essent Fatty & 25139400 & 2014 & U \\
\hline Zeng X & Acids. & 29673358 & 2018 & L \\
\hline
\end{tabular}




\begin{tabular}{|c|c|c|c|c|c|c|c|}
\hline \multicolumn{2}{|l|}{ jelection bias } & \multicolumn{2}{|c|}{ Performance bias } & \multicolumn{2}{|c|}{ Detection bias } & \multirow{2}{*}{\begin{tabular}{|c|} 
Attrition bias \\
incomplete \\
outcome \\
data
\end{tabular}} & \multirow{2}{*}{$\begin{array}{c}\begin{array}{c}\text { Reporting } \\
\text { bias }\end{array} \\
\text { selective } \\
\text { outcome } \\
\text { reporting }\end{array}$} \\
\hline $\begin{array}{c}\text { baseline } \\
\text { characteristic } \\
\mathrm{s}\end{array}$ & $\begin{array}{c}\text { Allocation } \\
\text { concealme } \\
\text { nt }\end{array}$ & $\begin{array}{l}\text { randomized } \\
\text { housing }\end{array}$ & $\begin{array}{c}\text { blinding of } \\
\text { investigato } \\
\text { rs }\end{array}$ & $\begin{array}{c}\text { random } \\
\text { outcome } \\
\text { assessment }\end{array}$ & \begin{tabular}{|c|} 
blinding \\
during \\
outcome \\
measuremen \\
$\mathrm{t}$
\end{tabular} & & \\
\hline$U$ & $U$ & $U$ & $U$ & 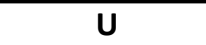 & $\mathbf{U}$ & $\mathbf{L}$ & $U$ \\
\hline U & $u$ & U & $u$ & U & $\mathbf{L}$ & U & $U$ \\
\hline $\mathbf{L}$ & U & U & U & $\mathbf{u}$ & $\mathbf{u}$ & $\mathbf{L}$ & U \\
\hline $\mathbf{L}$ & u & u & u & $\mathbf{u}$ & $\mathbf{u}$ & H & H \\
\hline U & u & U & U & $\mathbf{u}$ & U & $\mathbf{L}$ & $\mathbf{L}$ \\
\hline $\bar{L}$ & $U$ & U & U & U & U & $\bar{L}$ & U \\
\hline$U$ & $U$ & $U$ & $U$ & $U$ & $U$ & $\mathbf{L}$ & $U$ \\
\hline U & U & U & u & U & U & $\mathbf{L}$ & $\mathbf{L}$ \\
\hline U & U & U & u & u & u & $\mathbf{L}$ & U \\
\hline $\mathbf{L}$ & $U$ & $U$ & $U$ & U & $\mathbf{U}$ & $\mathbf{L}$ & $U$ \\
\hline U & $u$ & U & $u$ & U & u & U & $u$ \\
\hline U & U & U & U & $\mathbf{u}$ & $\mathbf{L}$ & H & U \\
\hline$U$ & $U$ & $U$ & $U$ & $\mathrm{U}$ & U & $\mathbf{L}$ & $\mathbf{L}$ \\
\hline $\mathbf{L}$ & $U$ & $U$ & $U$ & $U$ & $U$ & $\bar{L}$ & $\bar{L}$ \\
\hline $\mathbf{L}$ & $U$ & $U$ & $U$ & $U$ & $U$ & $\mathbf{L}$ & $U$ \\
\hline$U$ & $U$ & $U$ & $U$ & $\mathrm{U}$ & $U$ & $\mathbf{L}$ & $\mathbf{L}$ \\
\hline $\mathbf{L}$ & $U$ & $U$ & $U$ & $U$ & $U$ & $U$ & $U$ \\
\hline $\mathbf{L}$ & U & $U$ & $U$ & $U$ & U & $\mathbf{L}$ & $U$ \\
\hline$U$ & $\mathrm{U}$ & $\mathrm{U}$ & U & U & $U$ & $\mathbf{L}$ & U \\
\hline$U$ & 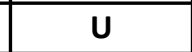 & $U$ & $U$ & $\mathrm{U}$ & $U$ & $\bar{L}$ & $U$ \\
\hline$U$ & $U$ & $U$ & $U$ & $U$ & $U$ & $\mathbf{L}$ & $U$ \\
\hline$U$ & $U$ & $U$ & $U$ & $U$ & $U$ & $\mathbf{L}$ & $U$ \\
\hline $\mathbf{L}$ & U & $U$ & U & 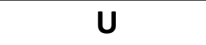 & U & $U$ & $U$ \\
\hline$U$ & $U$ & $U$ & $U$ & $U$ & $\mathrm{U}$ & $U$ & $\mathbf{L}$ \\
\hline $\mathbf{L}$ & $u$ & $u$ & $U$ & $U$ & $\mathrm{U}$ & $\mathbf{L}$ & $U$ \\
\hline U & u & U & U & U & u & H & u \\
\hline $\mathbf{L}$ & $U$ & $U$ & $U$ & 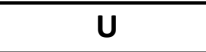 & $\mathbf{U}$ & $\mathrm{H}$ & $U$ \\
\hline $\mathbf{L}$ & $U$ & $U$ & $U$ & $U$ & $U$ & $\mathrm{H}$ & $U$ \\
\hline $\mathbf{L}$ & $U$ & $U$ & $U$ & $U$ & $U$ & $\mathbf{L}$ & $U$ \\
\hline$U$ & $U$ & $U$ & U & $\mathrm{U}$ & 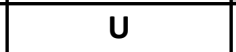 & $U$ & $U$ \\
\hline$U$ & $U$ & $U$ & $U$ & $U$ & U & $\mathbf{L}$ & $\mathbf{L}$ \\
\hline $\bar{U}$ & $\mathrm{U}$ & $\bar{U}$ & U & U & $\bar{U}$ & $\bar{L}$ & $\mathrm{U}$ \\
\hline $\mathrm{H}$ & $\mathrm{U}$ & $\mathrm{U}$ & $\mathrm{U}$ & $U$ & $\mathbf{L}$ & $\bar{L}$ & $\bar{L}$ \\
\hline$U$ & $U$ & $U$ & $U$ & 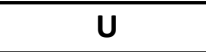 & $\mathbf{U}$ & $\mathbf{L}$ & $\mathbf{L}$ \\
\hline$U$ & $U$ & $U$ & $U$ & $U$ & $u$ & $\mathbf{L}$ & $\mathbf{L}$ \\
\hline H & $U$ & $U$ & $U$ & $U$ & $U$ & $\mathrm{H}$ & H \\
\hline $\mathrm{H}$ & $U$ & $\mathbf{U}$ & $U$ & $\mathrm{U}$ & $U$ & $\mathrm{H}$ & $\mathbf{H}$ \\
\hline $\mathbf{U}$ & $U$ & $U$ & $U$ & $\mathbf{U}$ & $\mathbf{U}$ & $\mathbf{L}$ & $\mathbf{L}$ \\
\hline $\mathbf{L}$ & $U$ & U & $U$ & $U$ & $U$ & U & $U$ \\
\hline$U$ & $U$ & $U$ & $U$ & $U$ & $U$ & $\mathbf{H}$ & $U$ \\
\hline $\mathbf{L}$ & $U$ & $U$ & $U$ & $U$ & $\mathbf{U}$ & $\mathbf{L}$ & $U$ \\
\hline $\mathbf{U}$ & $U$ & $U$ & $U$ & $U$ & $\mathbf{U}$ & $\mathbf{L}$ & $\mathbf{L}$ \\
\hline
\end{tabular}




\begin{tabular}{|c|c|c|c|c|c|c|c|}
\hline $\mathbf{L}$ & $U$ & $U$ & $U$ & $U$ & $U$ & $\mathbf{L}$ & $U$ \\
\hline L & $U$ & $\mathrm{U}$ & $U$ & $U$ & $U$ & $\mathrm{H}$ & $U$ \\
\hline $\mathbf{U}$ & $U$ & $U$ & $U$ & $U$ & $\mathrm{U}$ & $\mathrm{H}$ & $H$ \\
\hline $\mathbf{L}$ & $U$ & $U$ & $U$ & $U$ & $U$ & $\mathrm{H}$ & $H$ \\
\hline $\mathbf{L}$ & $U$ & $U$ & $U$ & $U$ & $U$ & $\mathbf{L}$ & $U$ \\
\hline $\mathbf{U}$ & $U$ & $U$ & $U$ & $U$ & $U$ & $U$ & $U$ \\
\hline $\mathbf{L}$ & $U$ & $U$ & $U$ & $U$ & $\mathrm{U}$ & $\mathbf{L}$ & $\mathbf{L}$ \\
\hline $\mathrm{H}$ & $U$ & $\mathbf{U}$ & $U$ & $U$ & $U$ & $\mathbf{L}$ & $\mathbf{L}$ \\
\hline $\mathbf{U}$ & $u$ & $\mathrm{U}$ & $\mathrm{U}$ & $\mathrm{U}$ & $\mathrm{U}$ & $L$ & $\mathrm{~L}$ \\
\hline $\mathbf{U}$ & $U$ & $\mathrm{U}$ & $U$ & $U$ & $U$ & $\mathbf{L}$ & $\mathbf{L}$ \\
\hline $\mathbf{U}$ & $U$ & $u$ & $U$ & U & $U$ & $\mathbf{L}$ & $\mathbf{L}$ \\
\hline $\mathbf{L}$ & $U$ & $U$ & $U$ & $U$ & $U$ & $U$ & $U$ \\
\hline $\mathrm{H}$ & $U$ & $\mathbf{U}$ & $\mathbf{U}$ & $U$ & $\mathbf{U}$ & $\mathbf{L}$ & $\mathbf{L}$ \\
\hline $\mathbf{L}$ & $U$ & $\mathrm{U}$ & $U$ & $U$ & $U$ & $\mathbf{L}$ & $\mathbf{L}$ \\
\hline $\mathbf{U}$ & $U$ & $\mathbf{U}$ & $U$ & $U$ & $U$ & $\mathbf{L}$ & $\mathrm{L}$ \\
\hline$L$ & $\mathrm{U}$ & $\mathrm{U}$ & $\mathrm{U}$ & $\mathrm{U}$ & $\mathrm{U}$ & $\mathbf{L}$ & $\mathrm{U}$ \\
\hline $\mathbf{L}$ & $U$ & $\mathrm{U}$ & $U$ & $U$ & $\mathrm{U}$ & $\mathbf{L}$ & $\mathrm{U}$ \\
\hline $\mathbf{U}$ & $U$ & $\mathrm{U}$ & $U$ & $U$ & $\mathrm{U}$ & $\mathbf{L}$ & $\mathbf{L}$ \\
\hline $\mathbf{L}$ & $U$ & $U$ & $U$ & $U$ & $U$ & $\mathbf{H}$ & $U$ \\
\hline $\mathbf{U}$ & $U$ & $U$ & $\mathrm{U}$ & $U$ & $\mathrm{U}$ & $\mathbf{H}$ & $\mathrm{U}$ \\
\hline $\mathbf{U}$ & $U$ & $\mathbf{U}$ & $U$ & $u$ & $U$ & $\mathbf{L}$ & $\mathrm{U}$ \\
\hline $\mathbf{U}$ & $U$ & $\mathrm{U}$ & $U$ & $U$ & $L$ & $U$ & $\mathbf{L}$ \\
\hline$L$ & $\mathrm{U}$ & $\mathrm{U}$ & $u$ & $\mathrm{U}$ & $\mathrm{U}$ & $L$ & $\mathrm{U}$ \\
\hline $\bar{L}$ & $U$ & $U$ & $U$ & $U$ & $\mathrm{U}$ & $\mathbf{L}$ & $\mathrm{U}$ \\
\hline $\mathbf{U}$ & $U$ & $\mathbf{U}$ & $U$ & $U$ & $U$ & $\mathbf{L}$ & $\mathbf{U}$ \\
\hline $\mathbf{L}$ & $U$ & $U$ & $U$ & $U$ & $U$ & $\mathrm{H}$ & $U$ \\
\hline $\mathbf{L}$ & $U$ & 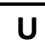 & $\mathrm{U}$ & $U$ & $U$ & $\mathbf{L}$ & $\mathrm{U}$ \\
\hline $\mathbf{L}$ & $U$ & $U$ & $U$ & $U$ & $U$ & $\mathbf{L}$ & $\mathrm{U}$ \\
\hline $\mathbf{L}$ & U & $\mathbf{U}$ & $U$ & U & $\mathbf{U}$ & $\mathbf{L}$ & $\mathbf{L}$ \\
\hline L & U & U & U & $U$ & U & L & $\mathbf{L}$ \\
\hline $\mathbf{L}$ & $U$ & $U$ & $U$ & $U$ & $U$ & $U$ & $U$ \\
\hline $\mathbf{L}$ & $U$ & $\mathrm{U}$ & $\mathbf{U}$ & $\mathbf{U}$ & $\mathbf{U}$ & $\mathbf{L}$ & $\mathrm{U}$ \\
\hline$U$ & $U$ & $\mathrm{U}$ & $U$ & $U$ & $U$ & $U$ & $\mathbf{U}$ \\
\hline$U$ & $U$ & $\mathrm{U}$ & $U$ & $U$ & $\mathrm{U}$ & $\mathbf{U}$ & $\mathrm{U}$ \\
\hline$U$ & $U$ & $U$ & $U$ & $\mathrm{U}$ & $\bar{U}$ & $\mathbf{L}$ & $\mathbf{L}$ \\
\hline$U$ & $U$ & $\mathrm{U}$ & $U$ & $U$ & $\mathrm{U}$ & $\mathbf{L}$ & $\mathbf{L}$ \\
\hline $\mathbf{L}$ & $U$ & $U$ & $U$ & $U$ & $U$ & $U$ & $U$ \\
\hline $\mathbf{L}$ & $U$ & $U$ & $U$ & $U$ & $U$ & $\mathrm{~L}$ & $U$ \\
\hline$U$ & $U$ & $U$ & $\mathbf{L}$ & $U$ & $U$ & $U$ & $U$ \\
\hline $\mathbf{L}$ & $U$ & $\mathrm{U}$ & $U$ & $U$ & $U$ & $\mathbf{L}$ & $\mathbf{U}$ \\
\hline$U$ & 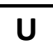 & $U$ & $U$ & $U$ & $U$ & $\mathrm{H}$ & $\mathbf{L}$ \\
\hline$U$ & $U$ & $U$ & $U$ & $U$ & $U$ & $\mathbf{L}$ & $\mathbf{L}$ \\
\hline $\mathbf{L}$ & $U$ & $\mathrm{U}$ & $U$ & $U$ & $\mathrm{U}$ & $\mathbf{L}$ & $\mathbf{L}$ \\
\hline $\mathbf{L}$ & $U$ & $\bar{U}$ & $U$ & $U$ & $U$ & $U$ & $U$ \\
\hline $\mathbf{L}$ & $U$ & $U$ & $U$ & $U$ & $U$ & $\mathbf{H}$ & $\mathrm{U}$ \\
\hline$U$ & $U$ & $\mathrm{U}$ & $U$ & $U$ & 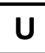 & $\mathbf{U}$ & $H$ \\
\hline $\mathrm{H}$ & $U$ & $U$ & $U$ & $U$ & $U$ & $\mathbf{L}$ & $\mathbf{L}$ \\
\hline$U$ & $\bar{U}$ & $U$ & $U$ & $U$ & $U$ & $\mathbf{L}$ & $\mathbf{L}$ \\
\hline $\bar{U}$ & $U$ & $U$ & $U$ & $\bar{U}$ & $U$ & $\bar{L}$ & $\bar{L}$ \\
\hline
\end{tabular}




\begin{tabular}{|c|c|c|c|c|c|c|c|}
\hline $\mathbf{L}$ & $\mathbf{U}$ & $\mathbf{U}$ & $\mathbf{U}$ & $\mathbf{U}$ & $\mathbf{U}$ & $\mathbf{U}$ & $\mathbf{U}$ \\
\hline $\mathbf{L}$ & $\mathbf{U}$ & $\mathbf{U}$ & $\mathbf{U}$ & $\mathbf{U}$ & $\mathbf{U}$ & $\mathbf{U}$ & $\mathbf{U}$ \\
\hline $\mathbf{U}$ & $\mathbf{U}$ & $\mathbf{U}$ & $\mathbf{U}$ & $\mathbf{L}$ & $\mathbf{U}$ & H & $\mathbf{U}$ \\
\hline $\mathbf{L}$ & $\mathbf{U}$ & $\mathbf{U}$ & $\mathbf{U}$ & $\mathbf{U}$ & $\mathbf{U}$ & $\mathbf{L}$ & $\mathbf{U}$ \\
\hline $\mathbf{U}$ & $\mathbf{U}$ & $\mathbf{U}$ & $\mathbf{U}$ & $\mathbf{U}$ & $\mathbf{U}$ & $\mathrm{H}$ & $\mathbf{U}$ \\
\hline $\mathbf{U}$ & $\mathbf{U}$ & $\mathbf{U}$ & $\mathbf{U}$ & $\mathbf{L}$ & $\mathbf{U}$ & $\mathrm{H}$ & $\mathbf{U}$ \\
\hline H & $\mathbf{U}$ & $\mathbf{U}$ & $\mathbf{U}$ & $\mathbf{U}$ & $\mathbf{U}$ & $\mathbf{L}$ & $\mathbf{U}$ \\
\hline $\mathbf{L}$ & $\mathbf{U}$ & $\mathbf{U}$ & $\mathbf{U}$ & $\mathbf{U}$ & $\mathbf{U}$ & $\mathrm{H}$ & $\mathbf{U}$ \\
\hline $\mathbf{L}$ & $\mathbf{U}$ & $\mathbf{U}$ & $\mathbf{U}$ & $\mathbf{U}$ & $\mathbf{U}$ & $\mathbf{U}$ & $\mathbf{U}$ \\
\hline $\mathbf{U}$ & $\mathbf{U}$ & $\mathbf{U}$ & $\mathbf{U}$ & $\mathbf{U}$ & $\mathbf{U}$ & $\mathbf{U}$ & $\mathbf{U}$ \\
\hline $\mathbf{U}$ & $\mathbf{U}$ & $\mathbf{U}$ & $\mathbf{U}$ & $\mathbf{U}$ & $\mathbf{U}$ & $\mathbf{H}$ & $\mathbf{U}$ \\
\hline $\mathbf{U}$ & $\mathbf{U}$ & $\mathbf{U}$ & $\mathbf{U}$ & $\mathbf{U}$ & $\mathbf{U}$ & $\mathbf{L}$ & $\mathbf{U}$ \\
\hline
\end{tabular}




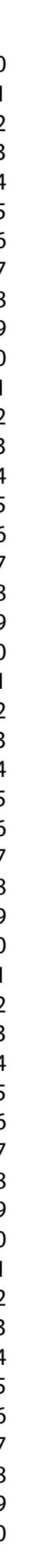

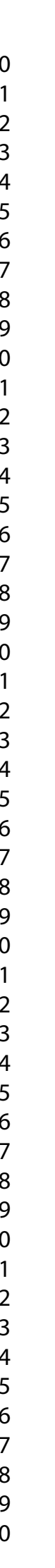

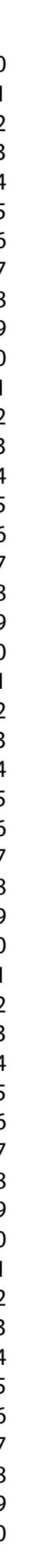

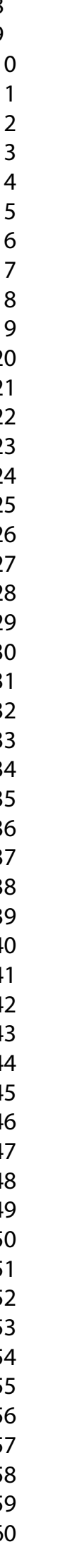

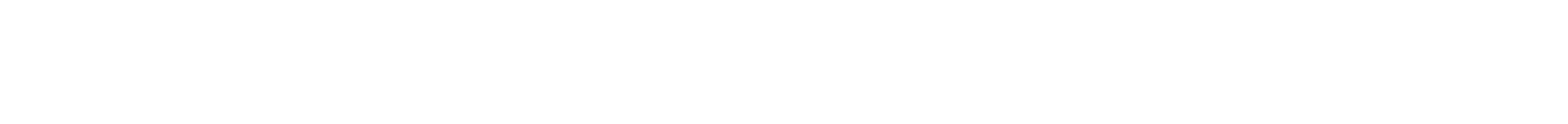

1
2
3
4
5
6
7
8
9
10
11
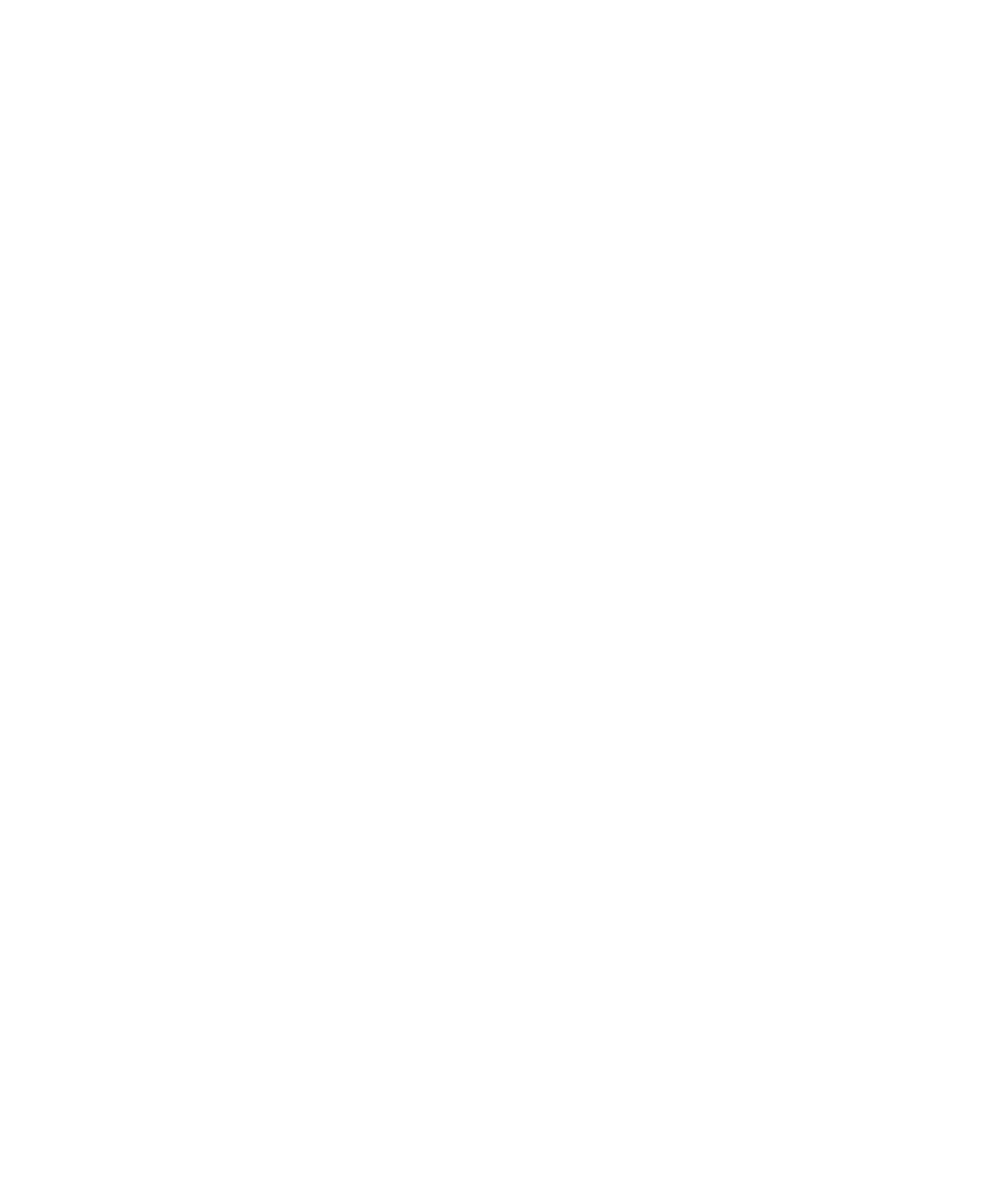


\section{Page 57 of 68
Supplementary Figure 1}

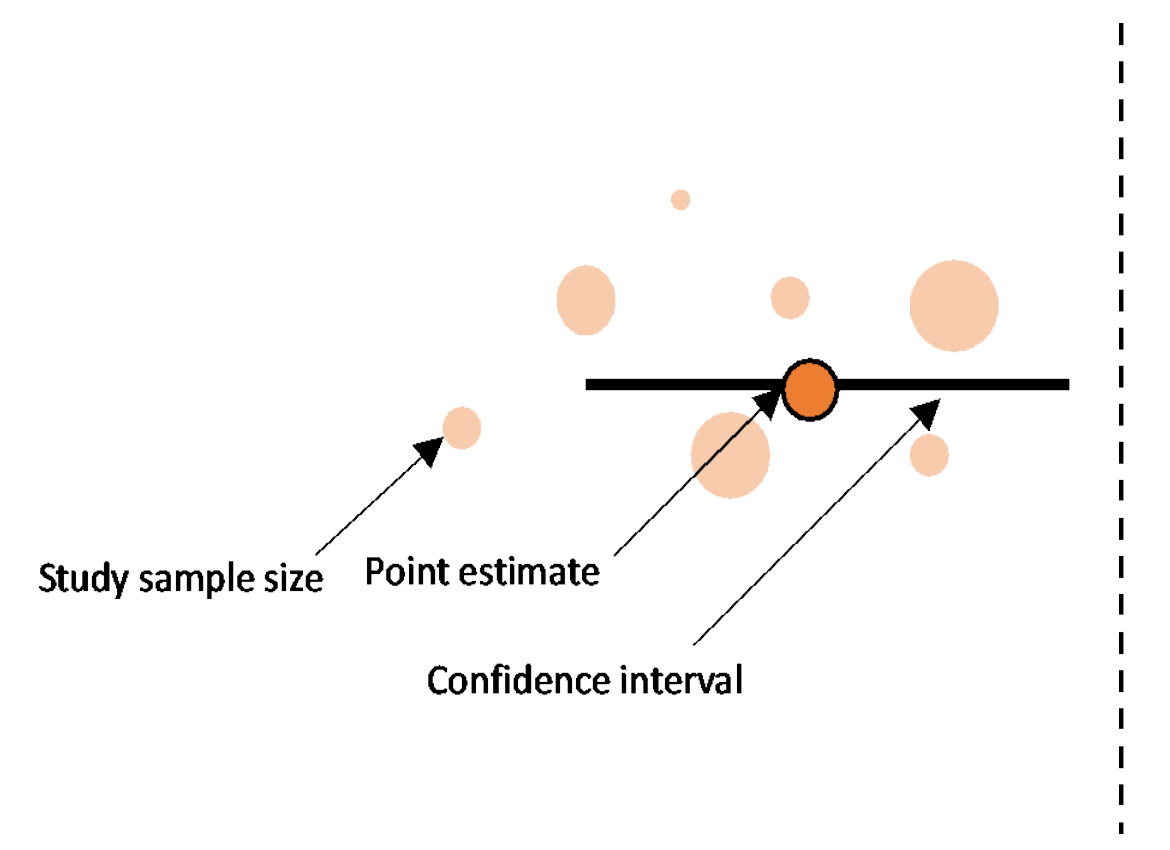




\section{Supplementary Figure 2}

A

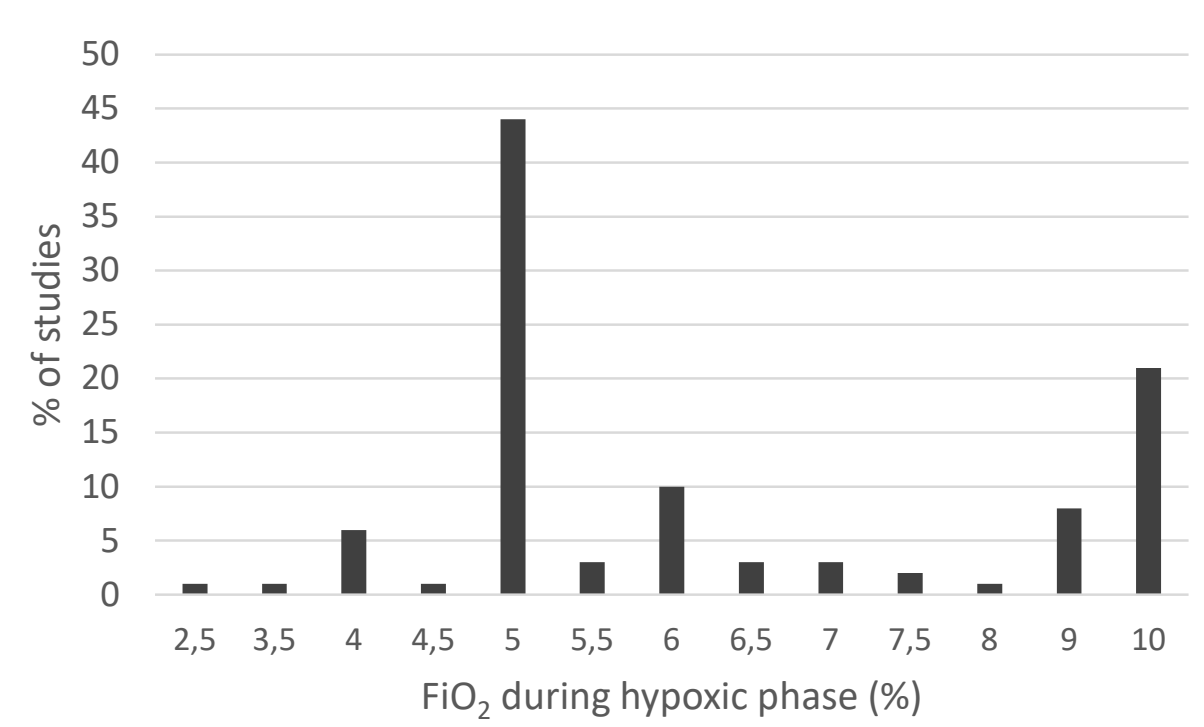

B

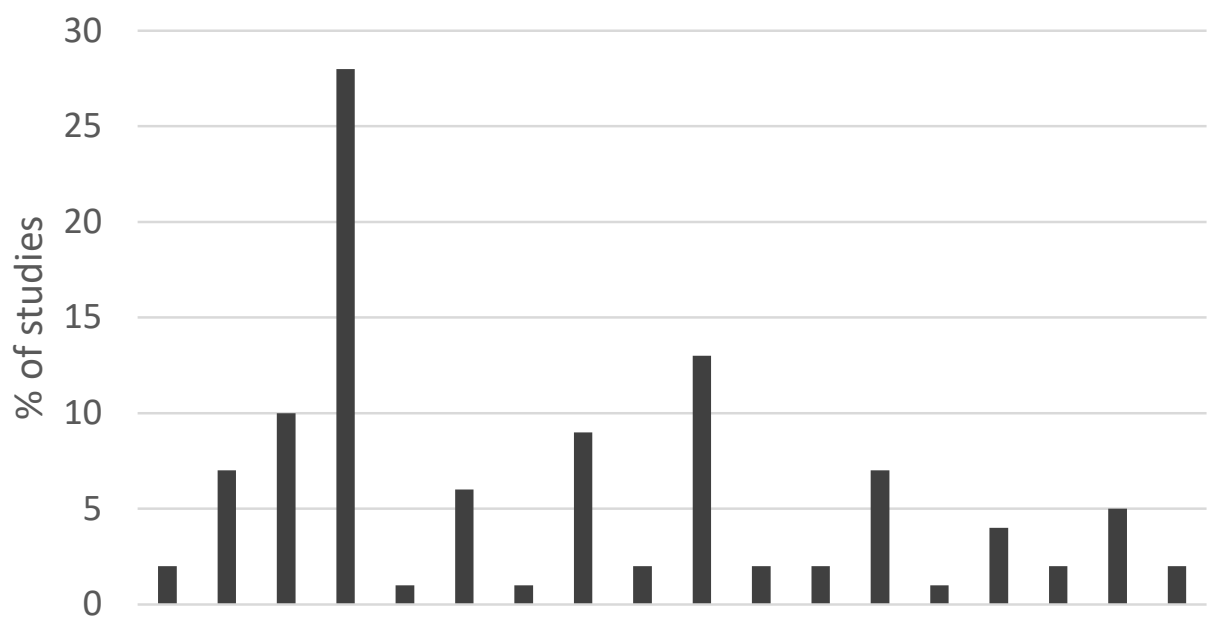

$10 \quad 15 \quad 20 \quad 30 \quad 35 \quad 40 \quad 45 \quad 60 \quad 80 \quad 90 \quad 100105120160180210240360$ Duration of hypoxic phase (seconds)
C

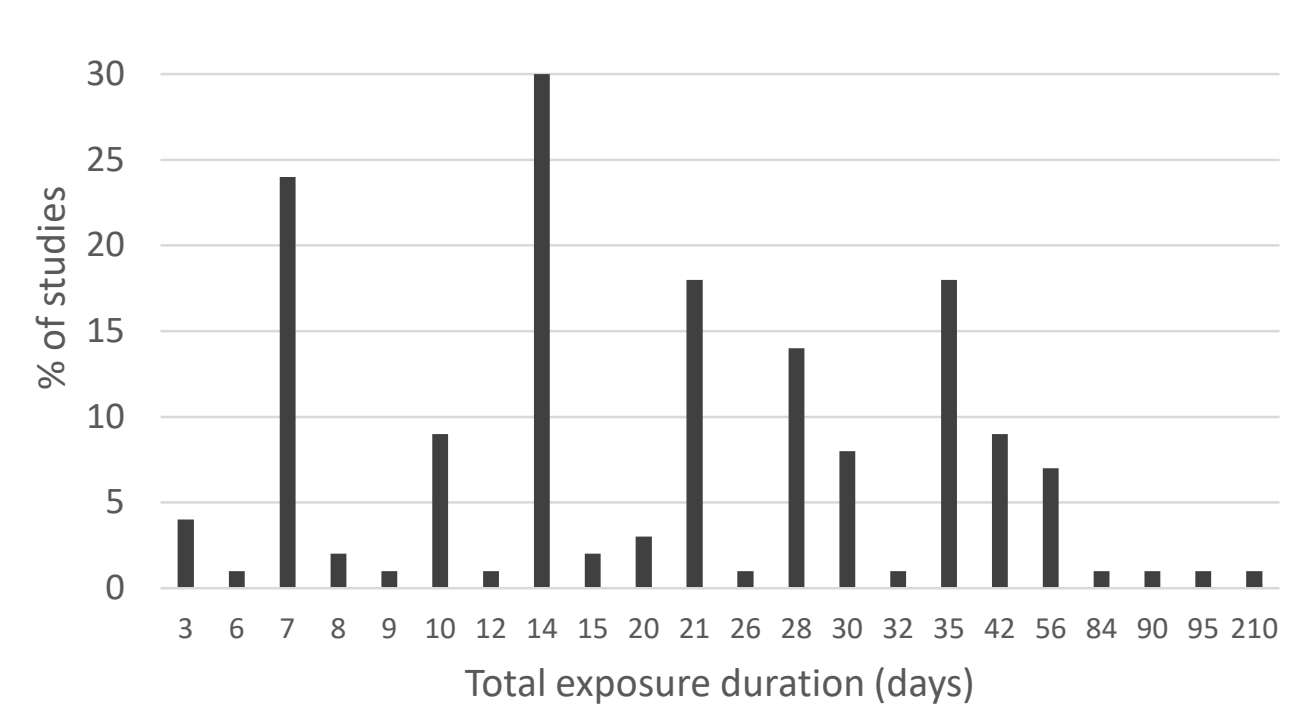

D

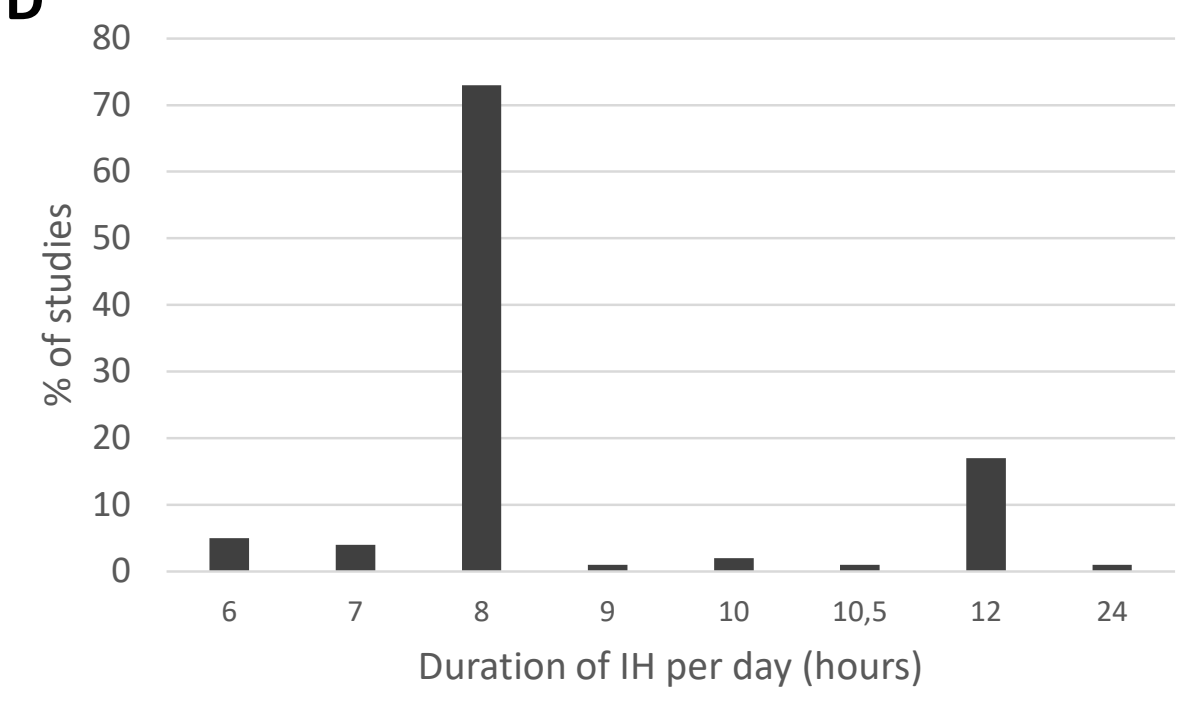




\section{Page 59 of $68 \quad$ European Respiratory Journal Supplementary Figure 3A}

1

2

$3 \begin{array}{ll}\text { Yang_2019_3 } \\ \text { Liu P-A_2019_7 }\end{array}$

4 Liu P-A_2019_7

5 Liu P-C_2019_7

5 Takahashi K-A_2018_8

6 Takahashi K-B_2018_8

Mentek M_2018_10

7 Guan P-A_2018_12

8 Guan P-B_C_2018_12

Ribon-Demars A-A_2018_16

9 Ribon-Demars A-B_2018_16

10 Arnaud C-A_2018_19

10 Arnaud C-B_2018_19

Wu JG-A 201820

11 Wu JG-B_2018_20 Wu JG-C_2018_20

12 Wu JG-D_2018_20

13 Chen L-A_2017_21

13 Chen L-B_2017_21

14 Chen L-C_2017_21

14 Ren H-A_2017_22

15 Ren H-B_2017_22

15 Ren H-C_2017_22

16 Lu W-A_2017_28

17 Lu W-C_2017_28

17 Lu W-A_2017_29

18 Lu W-B_2017_29

19 Lu W-D_2017_29

19 Moya EA_2016_37

20 Diogo LN_2015_40

21 Moreau JM-A_2015_42 Moreau JM-B_2015_42

22 Souza GM_2015_44

Krause BJ_2015_45

23 Schulz R-A_2014_54

Schulz R-B_2014 54

24 Hung MW-A_2013_59 Hung MW-B_2013_59

25 Hung MW-F_2013_59 Guo QH-A_2013_60

26 Guo QH-B_2013_60 Guo QH-C_2013_60

27 Guo QH-D_2013_60 Guo QH-E_2013 60

28 Fenik VB-A_2012_66 Fenik VB-B_2012_66

29 Fenik VB-C_2012_66 Del Rio R_2012_67

30 Raghuraman G_2011_76 Coleman CG-A 2010 77

31 Coleman CG-B_2010_77

32 Ray AD_2007_91

32 Huang J_2007_92

33 Zoccal DB_2007_95

34 Hui AS-B_2003_102

34 Hui AS-C_2003_102

35 Hui AS-D_2003_102

35 Fletcher EC_1992_109

36 Belaidi E-A_2009_110

$3 \longdiv { \text { RE Model } }$

38

39

40

$\longmapsto: 0.52 \% \quad 15.70[-16.02,47.42]$

$1.22 \% 37.70[22.18,53.22]$ $1.97 \% 40.00[35.16,44.84]$ $1.99 \% 10.00$ [ $5.62,14.38]$ $2.04 \% 5.00[1.71,8.29]$ $2.04 \% 2.00[-1.29,5.29]$ $1.86 \% 12.50$ [ $5.82,19.18]$ $2.05 \% 11.00$ [ 8.12, 13.88] $2.05 \% 8.00[5.12,10.88]$ $2.07 \% 2.00[-0.26,4.26]$ $1.21 \% 21.00[5.36,36.64]$ $1.24 \% 25.00$ [ $9.78,40.22]$ $2.09 \% 5.00$ [ 3.61, 6.39] $2.08 \% 16.00[13.81,18.19]$ $1.75 \% \quad 1.22[-7.00,9.44]$ $1.71 \% 14.28$ [ $5.56,23.00]$ $1.73 \% 18.56[10.05,27.07]$ $1.75 \% 24.62[16.42,32.82]$ $1.71 \% 3.20[-5.61,12.01]$ $1.42 \% \quad 6.30[-6.37,18.97]$ $1.76 \% 10.50[2.42,18.58]$ $1.40 \% 19.44[6.55,32.33]$ $1.38 \% 28.28[15.07,41.49]$ $1.31 \% 25.90[11.69,40.11]$ $1.25 \% \quad 3.40[-11.68,18.48]$ $0.56 \% 24.20[-6.04,54.44]$ $0.76 \% 44.80[20.50,69.10]$ $1.55 \% 5.00[-5.96,15.96]$ $1.08 \% 24.70$ [ $6.86,42.54]$ $0.75 \% 30.00$ [ 5.50, 54.50] $1.02 \% 30.00[11.18,48.82]$ $0.72 \% 28.30$ [ $3.04,53.56]$ $1.86 \% 21.60[15.02,28.18]$ $1.93 \% 12.00[6.46,17.54]$ $1.32 \% \quad 0.00[-14.13,14.13]$ $0.98 \% 22.00$ [ $2.40,41.60]$ $1.99 \% 7.00[2.62,11.38]$ $1.51 \% 28.00[16.57,39.43]$ $1.81 \% 7.00[-0.38,14.38]$ $1.91 \% 24.00[18.24,29.76]$ $1.36 \% \quad 0.00[-13.43,13.43]$ $1.25 \% 9.00[-6.12,24.12]$ $1.53 \% 17.00$ [ $5.86,28.14]$ $1.54 \% 3.00[-8.09,14.09]$ $1.51 \% \quad 6.00[-5.43,17.43]$ $1.26 \% 9.80[-5.17,24.77]$ $1.56 \% 14.70$ [ $3.96,25.44]$ $1.40 \% 26.10[13.20,39.00]$ $1.83 \% 21.00[13.93,28.07]$ $0.68 \%-2.00[-28.37,24.37]$ $1.23 \%-1.00[-16.31,14.31]$ $1.58 \% 38.30[27.76,48.84]$ $2.06 \% 21.00[18.23,23.77]$ $1.32 \% \quad 7.00[-7.13,21.13]$ $1.83 \% 10.00[2.93,17.07]$ $0.34 \% \quad 14.00[-27.67,55.67]$ $1.86 \% 24.40[17.70,31.10]$ $1.93 \% 12.00$ [ 6.46, 17.54] $2.06 \% 12.00[9.23,14.77]$ $2.06 \% 3.00[0.23,5.77]$ $2.06 \% 2.00[-0.77,4.77]$ $2.06 \% 1.00[-1.77,3.77]$ $1.83 \% 1.00[-6.07,8.07]$ $1.16 \% 10.00[-6.39,26.39]$ $1.33 \% 23.30$ [ 9.44, 37.16] 
Supplementary Figure 3B

5 Yang_2019_3

6 Liu P-A_2019_7

7 Liu P-B_2019_7

8 Liu P-C_2019_7

9 Mentek M_2018_10

10 Guan P-A_2018_12

11 Guan P-B_2018_12

12 Guan P-C_2018_12

13 Ribon-Demars A-A_2018_16

14 Ribon-Demars A-B_2018_16

15 Ren H-A_2017_22

16 Ren H-B_2017_22

17 Ren H-C_2017_22

18 Moya EA_2016_37

19 Diogo LN 2015_40 Perim RR_2015_41

21

22

23

24

25

26

27

28

29

30

\section{1}

32

33 Hui AS-C_2003 102

34 Hui AS-D_2003_102

35 Fletcher EC_1992_109
$1.38 \%$

$2.42 \%$

$3.93 \%$

$4.10 \%$

$3.93 \%$

$3.99 \%$

$4.15 \%$

$4.19 \%$

$3.69 \%$

$2.58 \%$

$2.69 \%$

$2.86 \%$

$2.79 \%$

$1.33 \%$

$3.16 \%$

$4.02 \%$

$3.10 \%$

$2.65 \%$

$4.02 \%$

$2.88 \%$

$3.44 \%$

$3.70 \%$

$1.12 \%$

$3.37 \%$

$4.16 \%$

$4.16 \%$

$4.16 \%$

$4.16 \%$

$4.16 \%$

$3.70 \%$
$12.20[-14.06,38.46]$

$33.30[17.42,49.18]$

$25.00[19.74,30.26]$

20.00 [ 16.49, 23.51]

14.20 [ 8.97, 19.43]

$10.00[5.33,14.67]$

$9.00[6.12,11.88]$

$0.00[-2.26,2.26]$

$26.70[19.57,33.83]$

$20.70[6.01,35.39]$

$19.82[5.91,33.73]$

30.49 [17.79, 43.19]

34.30 [ 21.11, 47.49]

27.30 [ 0.32, 54.28]

25.70 [15.01, 36.39]

$9.00[4.62,13.38]$

$-2.00[-13.09,9.09]$

$14.00[-0.13,28.13]$

$6.00[1.62,10.38]$

16.00 [ $3.45,28.55]$

$10.30[1.44,19.16]$

$13.00[5.93,20.07]$

$7.00[-23.49,37.49]$

$16.00[6.70,25.30]$

$9.00[6.23,11.77]$

$6.00[3.23,8.77]$

$-4.00[-6.77,-1.23]$

$0.00[-2.77,2.77]$

$1.00[-1.77,3.77]$

$8.00[0.93,15.07]$

\section{6}

37 RE Model

38

39

40
$100.00 \% 12.79$ [ 9.03, 16.54] 
5 Liu P-A_2019_7

6 Liu P-B_2019_7

do Carmo JM_2018_9

8 Mentek M_2018_10

Lee MYK-A_2018_14

Lee MYK-B_2018_14

10 Lee MYK-C_2018_14

11 Lee MYK-D_2018_14

Krause BJ_2018_15

12 Ribon-Demars A-A_2018_16

13 Ribon-Demars A-B_2018_16

14 Ren H-A_2017_22

Ren H-B_2017_22

16 Nanduri J-A_2016_31

7 Nanduri J-B_2016_31

17 Moraes DJ_2016_32

18 Chen YC_2016_33

19 Sacramento JF-A_2016_35

20 Quintero M-A_2016_38

Quintero M-B 2016 38

21 Diogo LN_2015_40

22 Perim RR_2015_41

23 Moreau JM-A_2015_42

24 Souza GM_2015_44

25 Krause BJ_2015_45

26 Shirai M_2014_50

26 Olea E-A_2014_51

27 Olea E-B_2014_51

28 Sharpe AL_2013_55

29 Guo XL_2013_57

30 Hernández-Guerra M_2013_61

30 Yamamoto K_2013_62

31 Cunningham JT_2012 65

32 Del Rio R_2012_67

33 Knight WD_2011_71

34 Silva AQ_2011_74

35 Raghuraman G_2011_76

36 Coleman CG-B_2010_77

37 Huang J_2010_78

Kc P_2010_80

38 Del Rio R_2010_81

39 Iturriaga R_2009_83

40 González-Martín MC-B_2009_84

41 Huang J_2009_85

42 Marcus NJ-A_2009_86

43 Marcus NJ-C_2009_86

Marcus NJ-D 200986

44 Marcus NJ-E_2009_86

45 Marcus NJ-F 2009 86

46 Marcus NJ-G_2009_86

47 Marcus NJ-H_2009_86

48 Marcus NJ-J_2009_86

Marcus NJ-K_2009_86

49 Marcus NJ-L_2009_86

50 Marcus NJ-M_2009_86

1 Marcus NJ-N_2009_86

Hayashi T_2008_87
Dematteis M_2008_88

53 Gu H_2007_90

54 Ray AD_2007_91

55 Lin M_2007_93

Zoccal DB_2007_94

56 Zoccal DB_2007_95

57 Kumar GK_2006_96

58 Lai CJ-A_2006_97

2ai CJ-B_2006_97

59 Lai CJ-C_2006_97

60 Phillips SA_2006_98 Hinojosa-Laborde C-B_2005_99 Campen MJ_2005_100

Lefebvre B_2006_101

Phillips SA_2004_103

Tahawi Z-A_2001_105 Tahawi Z-B_2001_105 Tahawi Z-C_2001_105 Tahawi Z-D_2001_105 Tahawi Z-E_2001_105 Tahawi Z-F_2001_105 Greenberg HE_1999 106 Greenberg HE_1999_106 Fetcher_1992_108 Fletcher EC_1992_109

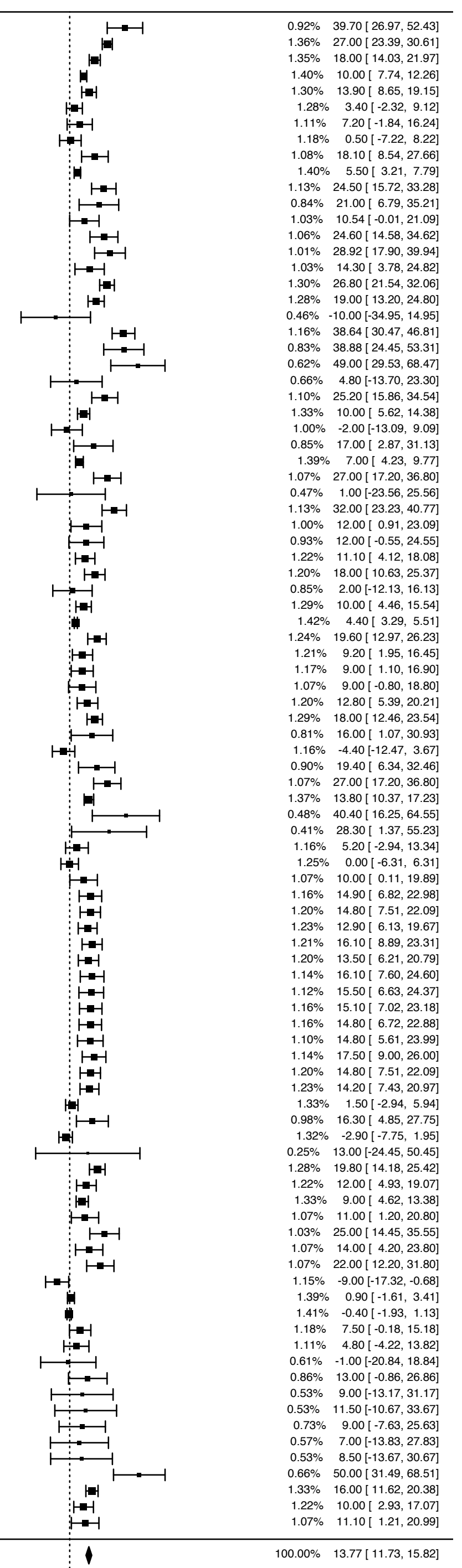

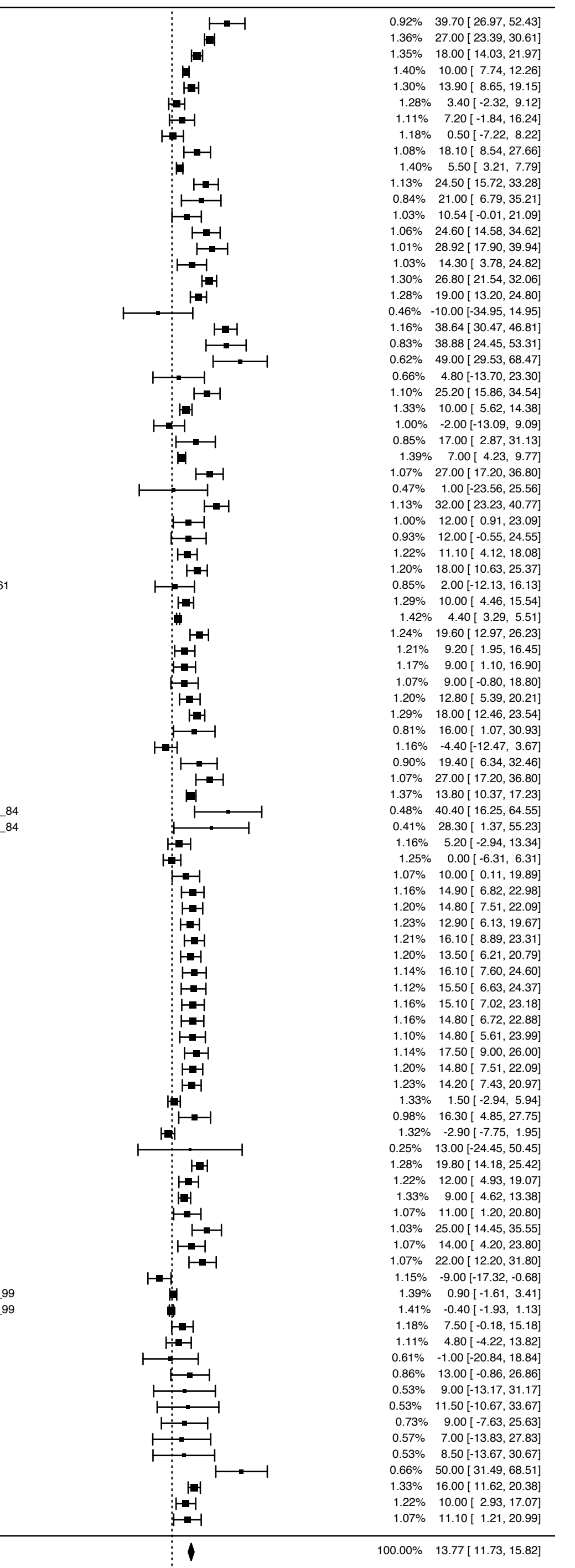

RE Model 


\section{Supplementary Figure 4}

\section{Subgroup}

strain $=$ C57BL 6

Random effects model

Heterogeneity: $I^{2}=55 \%, \tau^{2}=0.3417$

strain $=$ Fischer 344

Random effects model

Heterogeneity: not applicable

strain = sprague dawley

Random effects model

Heterogeneity: $I^{2}=68 \%, \tau^{2}=0.7981$

strain = wistar

Random effects model

Heterogeneity: $\left.\right|^{2}=63 \%, \tau^{2}=0,3890$

strain = wistar kyoto

Random effects model

Heterogeneity: not applicable

strain $=$ Zucker

Bandom effects model

Heterogeneity: not applicable

Random effects model

Heterogeneity: $I^{2}=67 \%, \tau^{2}=0.6437$

Residual heterogeneity: $I^{2}=66 \%$

Test for subgroup differences: $\chi_{5}^{2}=27.05$, df $=5(p<0.01)$
SMD $\quad 95 \%-\mathrm{Cl}$

$0.98[0.27 ; 1.69]$

$-0.39[-1.06 ; 0.28]$

$1.39[1.08 ; 1.70]$

$1.33[0.96 ; 1.70]$

$1.04[-0.02 ; 2.10]$

$0.31[-0.63 ; 1.24]$

$1.30[1.08 ; 1.53]$ 
Supplementary Figure 5

\section{Subgroup}

gender $=$ female

Random effects model

Heterogeneity: $I^{2}=0 \%, \tau^{2}=0$

gender $=$ male

Random effects model

Heterogeneity $l^{2}=76 \%, \tau^{2}=2.8535$

Random effects model

Heterogeneity: $I^{2}=78 \%, \tau^{2}=2.9540$

Residual heterogeneity. $I^{2}=74 \% \quad-10$

Test for subgroup differences: $\chi_{1}^{2}=14.28, \mathrm{df}=1(p<0.01)$

\section{Standardised Mean}

Difference

SMD

$95 \%-\mathrm{Cl}$

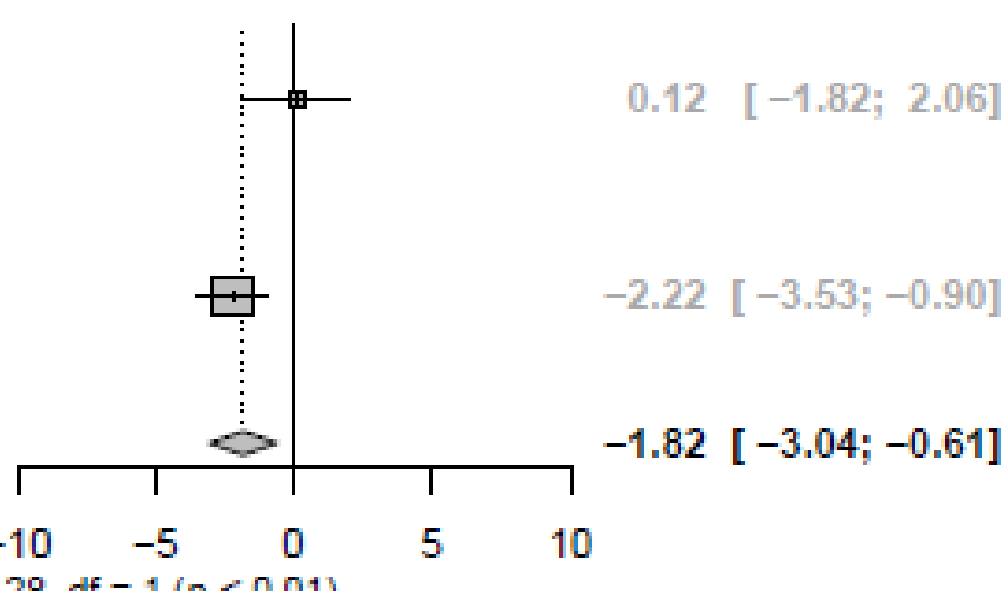




\section{Supplementary Figure 6}

\section{Subgroup}

species $=$ mice

Random effects model

Heterogeneity: $l^{2}=72 \%, \tau^{2}=0.9000$

species $=$ rat

Random effects model

Heterogeneity: $I^{2}=61 \%, \tau^{2}=0.3732$

\section{Random effects model}

Heterogeneity: $I^{2}=73 \%, \tau^{2}=0.7345$

Residual heterogeneity: $I^{2}=68 \%$

Test for subgroup differences: $\chi_{1}^{2}=3.69, \mathrm{df}=1(p=0.05)$

\section{Standardised Mean}

Difference

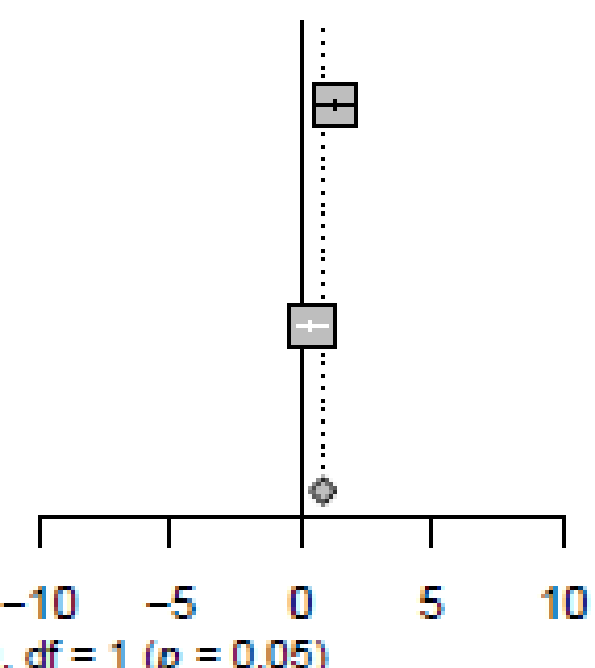

SMD

$95 \%-\mathrm{Cl}$

$1.29[0.44 ; 2.14]$

$0.40[-0.13 ; 0.93]$

$0.84 \quad[0.35 ; 1.32]$ 


\section{Supplementary Figure 7}

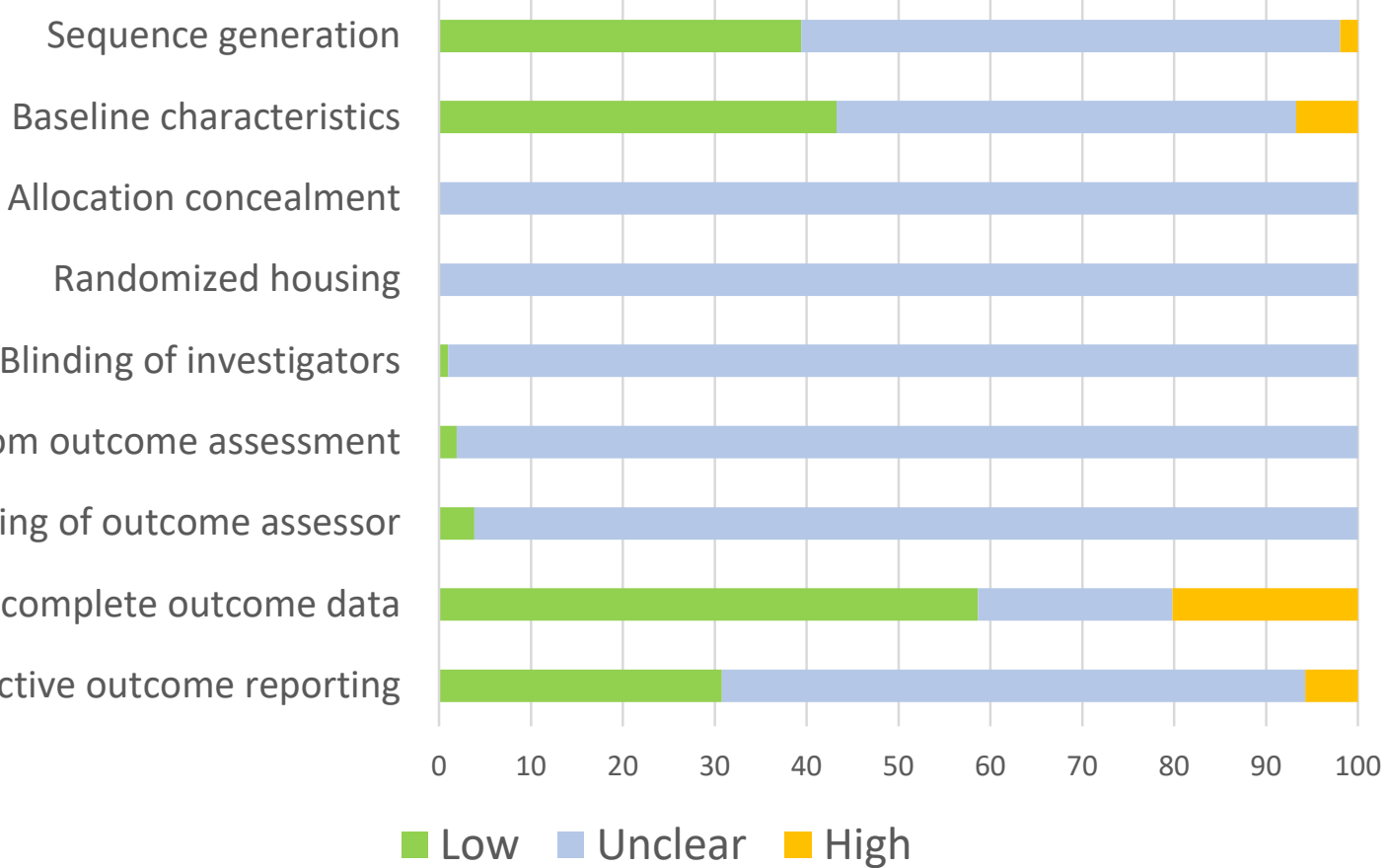




\section{Supplementary Figure 8}

European Respiratory Journal

Page 66 of 68

A
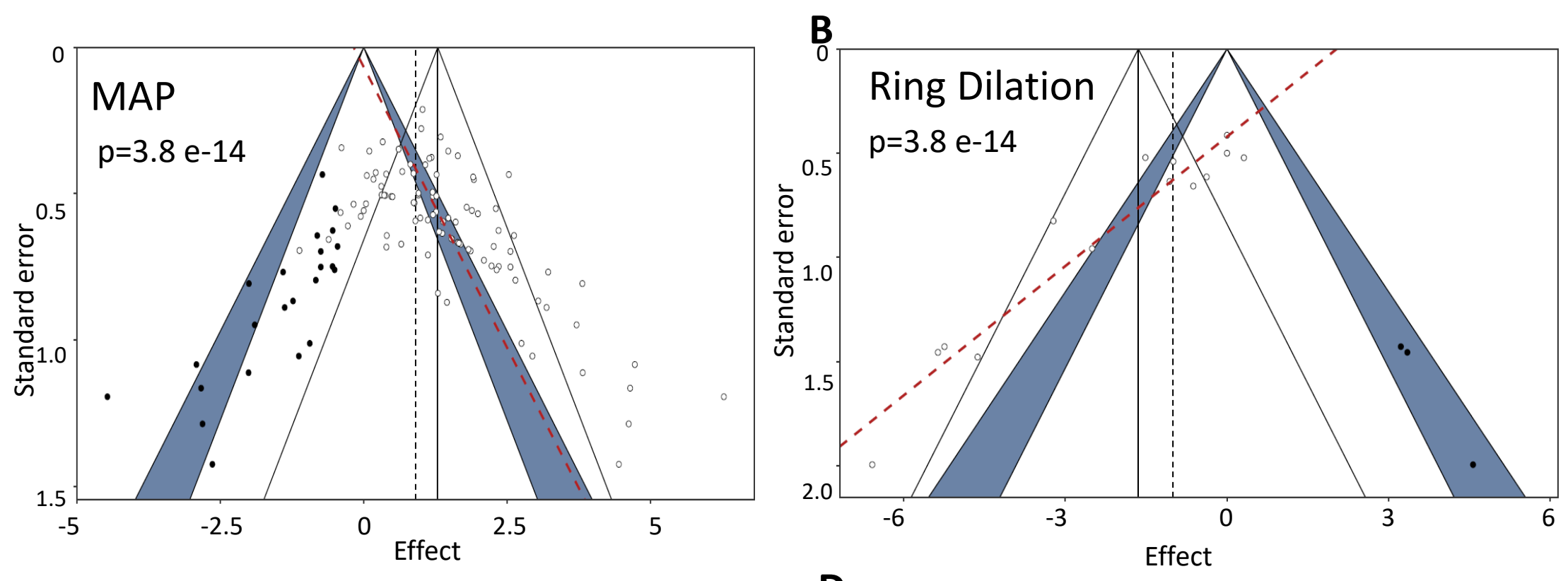

C

D
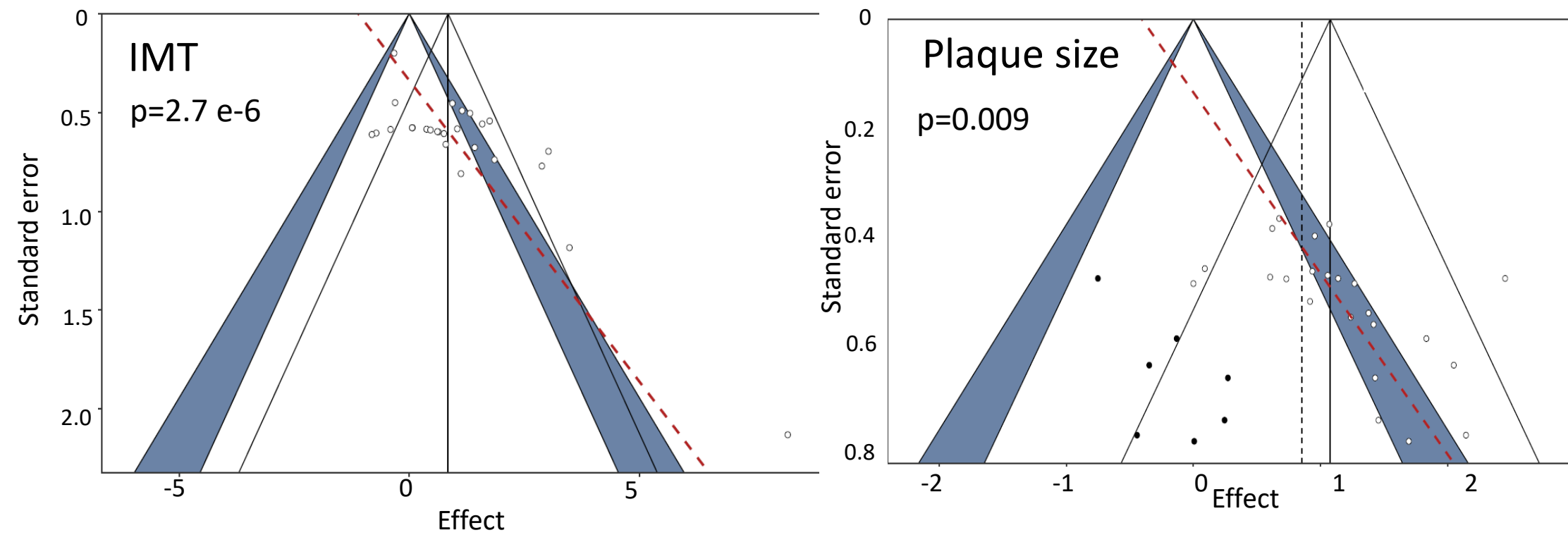


\section{ABSTRACT}

12 Structured summary 13

14

\section{INTRODUCTION}

16 Rationale

$1 \$$ Objectives 19

\section{METHODS}

22 Protocol and registration 23

2

25

27 Information sources $2 \$$

29 3. 32 33
\# Checklist item

Reported

on page \#

1 Identify the report as a systematic review, meta-analysis, or both.

1

2 Provide a structured summary including, as applicable: background; objectives; data sources; study eligibility criteria, participants, and interventions; study appraisal and synthesis methods; results; limitations; conclusions and implications of key findings; systematic review registration number.

3 Describe the rationale for the review in the context of what is already known.

4 Provide an explicit statement of questions being addressed with reference to participants, interventions, comparisons, outcomes, and study design (PICOS).

5 Indicate if a review protocol exists, if and where it can be accessed (e.g., Web address), and, if available, provide registration information including registration number.

6 Specify study characteristics (e.g., PICOS, length of follow-up) and report characteristics (e.g., years considered, language, publication status) used as criteria for eligibility, giving rationale.

7 Describe all information sources (e.g., databases with dates of coverage, contact with study authors to identify additional studies) in the search and date last searched.

8 Present full electronic search strategy for at least one database, including any limits used, such that it could be repeated.

9 State the process for selecting studies (i.e., screening, eligibility, included in systematic review, and, if applicable, included in the meta-analysis).

10 Describe method of data extraction from reports (e.g., piloted forms, independently, in duplicate) and any processes for obtaining and confirming data from investigators.

11 List and define all variables for which data were sought (e.g., PICOS, funding sources) and any assumptions and simplifications made.

12 Describe methods used for assessing risk of bias of individual studies (including specification of whether this was done at the study or outcome level), and how this information is to be used in any data synthesis.

13 State the principal summary measures (e.g., risk ratio, difference in means).

14 Describe the methods of handling data and combining results of studies, if done, including measures of consistency (e.g., $\mathrm{I}^{2}$ ) for each meta-analysis.

\section{2}

3

3-4 4

$4-5$ 4

PROSPERO

4

4

$4+$ PROSPERO 5 5 5 


\section{RESULTS}

14 Study selection 15 $1 \$$

Page 1 of 2 10 Study characteristics

\section{\# Checklist item}

15 Specify any assessment of risk of bias that may affect the cumulative evidence (e.g., publication bias, selective reporting within studies).

16 Describe methods of additional analyses (e.g., sensitivity or subgroup analyses, meta-regression), if done, indicating which were pre-specified.

17 Give numbers of studies screened, assessed for eligibility, and included in the review, with reasons for exclusions at each stage, ideally with a flow diagram.

18 For each study, present characteristics for which data were extracted (e.g., study size, PICOS, follow-up period) and provide the citations.

19 Present data on risk of bias of each study and, if available, any outcome level assessment (see item 12).

Risk of bias within studies

Results of individual studies

For all outcomes considered (benefits or harms), present, for each study: (a) simple summary data for each intervention group (b) effect estimates and confidence intervals, ideally with a forest plot.

Synthesis of results

21 Present results of each meta-analysis done, including confidence intervals and measures of consistency.

Risk of bias across studies

Present results of any assessment of risk of bias across studies (see Item 15).

Give results of additional analyses, if done (e.g., sensitivity or subgroup analyses, meta-regression [see Item 16]).
Reported on page \#

6

6

7+Figure 1

Supplementary Tables 1 and 2

9+

Supplementary

Figure 7 and supplementary table 3

8-9+Figures $2,3,4,5$

8-9+Figures $2,3,4,5$

$9+$

Supplementary Figure 7 and supplementary table 3

10+

supplementary figure 8+

Supplementary Table 4 
3

\begin{tabular}{|c|c|c|c|}
\hline Summary of evidence & 24 & $\begin{array}{l}\text { Summarize the main findings including the strength of evidence for each main outcome; consider their } \\
\text { relevance to key groups (e.g., healthcare providers, users, and policy makers). }\end{array}$ & $10-13$ \\
\hline Limitations & 25 & $\begin{array}{l}\text { Discuss limitations at study and outcome level (e.g., risk of bias), and at review-level (e.g., incomplete retrieval } \\
\text { of identified research, reporting bias). }\end{array}$ & 13 \\
\hline \multicolumn{4}{|l|}{ FUNDING } \\
\hline Funding & 27 & $\begin{array}{l}\text { Describe sources of funding for the systematic review and other support (e.g., supply of data); role of funders } \\
\text { for the systematic review. }\end{array}$ & 15 \\
\hline
\end{tabular}

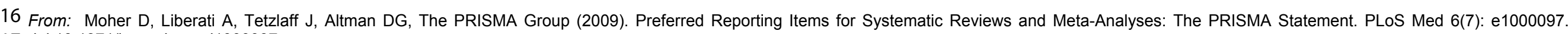
17 doi:10.1371/journal.pmed1000097

For more information, visit: www.prisma-statement.org.

Page 2 of 2 